\title{
Non-canonical HIF-1 stabilization is essential for intestinal tumorigenesis
}

Nadine Rohwer ${ }^{1}$, Sandra Jumpertz ${ }^{2,18}$, Merve Erdem ${ }^{2,18}$, Antje Egners ${ }^{2}$, Klaudia T. Warzecha $^{3}$, Athanassios Fragoulis ${ }^{2}$, Anja A. Kühl ${ }^{4}$, Rafael Kramann ${ }^{5}$, Sabine Neuss ${ }^{6}$, Ines Rudolph ${ }^{1}$, Tobias Endermann ${ }^{7}$, Christin Zasada ${ }^{8}$, Ivayla Apostolova ${ }^{9}$, Marco Gerling ${ }^{10}$, Stefan Kempa $^{8}$, Russell Hughes ${ }^{11}$, Claire E. Lewis ${ }^{11}$, Winfried Brenner ${ }^{9}$, Maciej B. Malinowski ${ }^{12,19}$, Martin Stockmann ${ }^{12}$, Lutz Schomburg ${ }^{7}$, William Faller ${ }^{13,20}$, Owen Sansom ${ }^{13}$, Frank Tacke ${ }^{3}$, Markus Morkel ${ }^{14}$ and Thorsten Cramer $^{2,15,16,17}$

${ }^{1}$ Hepatology and Gastroenterology, Charité, Campus Virchow-Klinikum, Berlin, Germany; ${ }^{2}$ Molecular Tumor Biology, Department of General, Visceral- and Transplantation Surgery, RWTH University Hospital, Aachen, Germany; ${ }^{3}$ Medicine III, RWTH University Hospital, Aachen, Germany; ${ }^{4}$ iPATH.Berlin - Core Unit of the Charité - Universitätsmedizin Berlin, corporate member of Freie Universität Berlin, Humboldt-Universität zu Berlin, and Berlin Institute of Health, Berlin, Germany; ${ }^{5}$ Medicine II, RWTH University Hospital, Aachen, Germany; ${ }^{6}$ Pathology, RWTH University Hospital, Aachen, Germany; ${ }^{7}$ Experimental Endocrinology, Charité, Campus Virchow-Klinikum, Berlin, Germany; ${ }^{8}$ Max-DelbrückCentrum, Berlin, Germany; ${ }^{9}$ Nuclear Medicine, Charité, Campus Virchow-Klinikum, Berlin, Germany; ${ }^{10}$ Biosciences and Nutrition, Karolinska Institutet, Stockholm, Sweden; ${ }^{11}$ Oncology and Metabolism, University of Sheffield Medical School, Sheffield, UK; ${ }^{12}$ Department of Surgery, Charité, Campus Virchow-Klinikum, Berlin, Germany; ${ }^{13}$ Cancer Research UK Beatson Institute, Glasgow, UK; ${ }^{14}$ Institute of Pathology, Charité, Campus Mitte, Berlin, Germany; ${ }^{15}$ NUTRIM School of Nutrition and Translational Research in Metabolism, Maastricht University, Maastricht, The Netherlands; ${ }^{16}$ ESCAM - European Surgery Center Aachen Maastricht, Germany and The Netherlands

\footnotetext{
${ }^{17}$ lead contact

${ }^{18}$ equal contribution

${ }^{19}$ present address: Department for General, Visceral, Vascular, and Pediatric Surgery, Saarland University Hospital, Homburg, Germany
} 
Rohwer et al., HIF-1 and intestinal tumorigenesis

${ }^{20}$ present address: The Netherlands Cancer Institute, Amsterdam, The Netherlands

Contact Information:

Thorsten Cramer, Molecular Tumor Biology, General, Visceral- and Transplantation Surgery,

RWTH University Hospital, Pauwelsstraße 30, 52074 Aachen, Germany; Phone: +49 241

8036353, e-mail: tcramer@ukaachen.de

Conflict of interest statement :

The authors have declared that no conflict of interest exists. 
Rohwer et al., HIF-1 and intestinal tumorigenesis

\section{Abstract}

The hypoxia-inducible transcription factor HIF-1 is appreciated as a promising target for cancer therapy. However, conditional deletion of HIF-1 and HIF-1 target genes in cells of the tumor microenvironment can result in accelerated tumor growth, calling for a detailed characterization of the cellular context to fully comprehend HIF-1's role in tumorigenesis. We dissected cell type-specific functions of HIF-1 for intestinal tumorigenesis by lineagerestricted deletion of the Hif1a locus. Intestinal epithelial cell-specific Hif1a loss reduced activation of wnt/ $\beta$-catenin, tumor-specific metabolism and inflammation, significantly inhibiting tumor growth. Deletion of Hif1a in myeloid cells reduced the expression of fibroblast-activating factors in tumor-associated macrophages resulting in decreased abundance of tumor-associated fibroblasts and robustly reduced tumor formation. Interestingly, hypoxia was detectable only sparsely and without spatial association with nuclear HIF-1 $\alpha$ in intestinal adenomas, pointing towards a functional importance of hypoxiaindependent, i.e. non-canonical HIF-1 stabilization that has not been previously appreciated. This adds a further layer of complexity to the regulation of HIF-1 $\alpha$ and suggests that hypoxia and HIF-1 $\alpha$ stabilization can be uncoupled in cancer. Collectively, our data show that HIF-1 is a pivotal pro-tumorigenic factor for intestinal tumor formation, controlling key oncogenic programs in both the epithelial tumor compartment and the tumor microenvironment. 
Rohwer et al., HIF-1 and intestinal tumorigenesis

\section{Introduction}

Colorectal cancer (CRC) ranks as the third most commonly diagnosed tumor in both sexes in the western world, causing a substantial amount of cancer-associated morbidity and mortality (1). In the last decade, molecular-targeted drugs have -in combination with conventional therapies- resulted in improved outcome of CRC patients (2). However, as also noted frequently for other solid tumors, these new generation treatments rarely result in improved outcome, but rather benefit small subgroups of CRC patients (3). Taken together, an urgent need to identify novel therapy targets exists, demonstrating the necessity for detailed characterization of the molecular CRC pathogenesis.

The hypoxia-inducible transcription factor 1 (HIF-1) is positively associated with the malignant progression of various tumor entities (4-7). While the role of HIF-1 for the pathogenesis of CRC has been addressed by different groups, results are conflicting and the precise function of HIF-1 for intestinal tumorigenesis remains elusive. Stabilization of HIF-1 $\alpha$, the regulatory component of HIF-1, in human $\mathrm{CRC}$ has been reported via immunohistochemistry, suggesting a pro-tumorigenic function (8-10). In line with these findings, inhibition of HIF-1 $\alpha$ in human CRC cell lines resulted in reduced xenograft growth $(11,12)$. Furthermore, pharmaceutical inhibition of HIF-1 $\alpha$ led to diminished growth of autochtonous as well as allograft murine CRC models via reduced angiogenesis and macrophage infiltration (13). On the other hand, transgenic activation of HIF-1 in intestinal epithelial cells (IEC) remained without effect on tumor formation in murine models of sporadic and colitis-associated colon cancer $(14,15)$. Moreover, IEC-specific loss of Hif1a did not affect tumor frequency in a chemical model of proximal intestinal tumorigenesis (16). These results illustrate that the precise role of HIF-1 for intestinal tumorigenesis remains elusive thus far.

While HIF-1 is widely appreciated as a promising target for cancer therapy (17), conditional deletion of HIF-1 and HIF-1 target genes in cells of the tumor microenvironment can result in 
Rohwer et al., HIF-1 and intestinal tumorigenesis

accelerated tumor growth (18-20). Against this background, a comprehensive analysis of HIF-1's role in tumorigenesis in order to translate the findings into the clinic can only be achieved by considering the cell- and tissue-specific context. Here, we present a detailed deconstruction of HIF-1's role in CRC initiation and progression in IEC- and myeloid cellspecific Hif1a knock-out mice $(21,22)$ using two murine tumor models: Chemically-induced colon tumors (AOM/DSS (combination of a azoxymethane plus dextran sulfate sodium for colitis-associated carcinogenesis) (23)) and the genetic APC ${ }^{\text {in }}$ model (24). This experimental approach enabled us to address the role of HIF-1 in neoplastic epithelial cells as well as in innate immune cells of the tumor microenvironment. We were able to unravel numerous specialized functions of HIF-1. In IECs, HIF-1 serves to induce inflammation, control wnt/ß-catenin activity and regulate tumor-specific metabolism. In addition, we identified myeloid HIF-1 as essential for the activation of tumor-associated fibroblasts. Of note, intratumoral hypoxia was a rare event, pointing towards an importance of hypoxiaindependent, i.e. non-canonical HIF-1 stabilization for intestinal tumorigenesis (25). Collectively, our data show that HIF-1 is a pivotal pro-tumorigenic factor, controlling key oncogenic programs in both the epithelial tumor compartment and the tumor microenvironment. 
Rohwer et al., HIF-1 and intestinal tumorigenesis

\section{Results}

\section{Epithelial Hif1a controls intestinal tumor growth on multiple levels}

IEC-specific loss of Hif1a (termed Hif1 $\mathrm{a}^{\mathrm{IEC}}$ ) was established by breeding villin-cre mice (26) with animals harbouring floxed Hif1a alleles (22). Conditional Hif1a deletion was characterized on various levels and found to be highly efficient (Figure S1A). Tumor size in both the AOM/DSS and APC min model was significantly decreased in Hif1a ${ }^{\mathrm{IEC}}$ mice (Figure 1A). We sought to identify the underlying molecular mechanisms and first characterized the activity of the wnt/ $\beta$-catenin pathway, the central oncogenic driver of $\mathrm{CRC}$. As can be seen in figure 1B-D, wnt-dependent gene expression is significantly reduced in adenomas of Hif1a mice in both tumor models, suggesting a functional role of HIF- 1 for wnt $/ \beta$-catenin activity in this setting. Next, we addressed the role of Hif1a for tumor-specific glucose metabolism as metabolic reprogramming represents an emerging hallmark of cancer and several glycolytic enzymes are transcriptionally controlled by HIF-1 (27). Mass spectrometry-based analysis of intratumoral glucose levels, routing of ${ }^{13} \mathrm{C}$-labelled glucose as well as in vivo imaging by PET/CT revealed diminished uptake and metabolization into lactate of glucose in tumors of Hif1a IEC mice (Figure 1E, F). Finally, we performed a comprehensive analysis of inflammatory activity as chronic inflammation is pro-tumorigenic in CRC (28). Hif1a ${ }^{\mathrm{IEC}}$ mice displayed reduced loss of body weight (Figure 2A) and colitis activity after DSS challenge (Figure 2B). Intestinal gene expression and protein secretion of pivotal pro-inflammatory factors were significantly lower in DSS-treated Hif1a ${ }^{\mathrm{IEC}}$ mice (Figure 2C, D). Experiments with small intestinal organoids were conducted to further address the contribution of IECs in this setting. After assuring efficient Hif1a deletion (Figure S2), organoids were subjected to different pro-inflammatory stimuli. These experiments nicely confirmed that the proinflammatory response of IECs critically depends on Hif1a (Figure 2E). Taken together, these data point towards a complex role for Hif1a in IECs during intestinal tumor formation, comprising inflammation, wnt/ $\beta$-catenin activity and metabolic reprogramming. 
Rohwer et al., HIF-1 and intestinal tumorigenesis

\section{Hif1a in myeloid cells controls intestinal tumor formation without affecting inflammation}

Macrophages in the tumor microenvironment exert a number of tumor-supporting functions and are positively associated with the malignant phenotype (29). We and others have shown that Hif1a is of pivotal importance for various aspects of macrophage function $(21,30)$. Against this background, we sought to characterize the role of Hif1a for intestinal tumor formation in macrophages. We found that myeloid cell-specific loss of Hif1a (termed Hif1a $\mathrm{a}^{\mathrm{MC}}$ ) resulted in a highly significant reduction of both tumor number and size (Fig. 3A). In order to identify the underlying mechanisms, we first analyzed the inflammatory response. Rather unexpectedly, various assays of inflammation (e.g. determination of weight loss (Fig. 3B), disease activity index (Fig. 3C)) as well as gene expression and protein production of established pro-inflammatory markers (Fig. 3D, E, F)) failed to show a difference of inflammatory activity between wildtype and Hif1 $\mathrm{a}^{\mathrm{MC}}$ mice.

\section{Hif1a-deficient tumor-associated macrophages migrate and function normally}

Next, we determined intratumoral macrophage numbers via immunohistochemistry (IHC). While macrophage abundance was clearly greater in adenomas compared to surrounding normal mucosa (not shown), no difference was detectable between the genotypes (Figure 4A). Intestinal leukocyte subsets were subsequently analyzed in more detail by flow cytometry. Tumor-bearing mice displayed a prominent increase in CD11c+ macrophages and CD11b+ dendritic cells, while CD11c- macrophages were reduced. The changes in myeloid subsets were comparable between wildtype and Hif1 $\mathrm{a}^{\mathrm{MC}}$ mice, except for a slightly more pronounced reduction of $\mathrm{CD} 11 \mathrm{C}$ - intestinal macrophages in tumor-bearing Hif1a $\mathrm{M}^{\mathrm{MC}}$ mice (Figure 4B). Intestinal lymphoid cell populations did not differ significantly between wildtype and Hif1 $\mathrm{a}^{\mathrm{MC}}$ mice (Figure 4B). Notably, tumor-bearing animals showed typical alterations of extraintestinal myeloid cells (31), including increase of monocytes in blood and bone marrow and accumulation of Gr1+ CD11b+ myeloid-derived suppressor cells (MDSC) in bone marrow, but not spleen (Figure S3). Extraintestinal myeloid cells did not differ between 
wildtype and Hif1 $\mathrm{a}^{\mathrm{MC}}$ mice. Next, we decided to analyze the direct tumor-supporting action of macrophages as these cells secrete numerous pro-tumorigenic factors (32). To this end, spheroids of $\mathrm{APC}^{\mathrm{min}}$ adenomas were stimulated with conditioned medium (CM) from primary murine macrophages. While we were able to detect a significant growth-promoting effect of macrophage CM, the loss of Hif1a did not affect the outcome (Figure 4C). As macrophages represent pivotal modulators of stem-like/progenitor cells (33), which are critical drivers of colonic carcinogenesis (34), we decided to quantify these cells in our experimental setting. Visualization of Lgr5 and Prox1, two established progenitor/stem-cell markers in intestinal tumors $(35,36)$, demonstrated robust presence of these cells in AOM/DSS adenomas, albeit without differences between the genotypes (Figure S4A). Furthermore, we took into consideration that other cells of myeloid origin might underlie the reduced tumor formation in Hif1a $\mathrm{a}^{\mathrm{MC}}$ mice. While mast cells can influence intestinal tumorigenesis under certain experimental conditions (37), no difference in intratumoral abundance of this cell type was noted, arguing against a functional importance of mast cells in our setting (Figure S4B).

\section{Hif1a in myeloid cells is essential for the activation of tumor-associated fibroblasts}

Myeloid cells in the tumor microenvironment are known to interact with various cell types, including tumor-associated fibroblasts (TAF). These cells are abundant in human CRC and significantly impact on disease progression $(38,39)$. TAFs were readily detectable via IHC in the stroma of $\mathrm{APC}^{\mathrm{min}}$ and AOM/DSS-induced adenomas (Figure 5A). Strikingly, deletion of Hif1a in myeloid cells resulted in greatly reduced numbers of TAFs in both tumor models (Figure 5A). This result pointed towards a crucial role of Hif1a in myeloid cells for TAF development. Interestingly, the importance of macrophages for fibroblast activation in the context of wound healing is well established $(40,41)$. To analyze this further, we focussed on alternatively activated macrophages (AAM) given their central role in the control of organ fibrosis (40). Expression of various pro-fibrotic genes in AAMs was readily detectable, but loss of Hif1a remained without effect (Figure S5A). To achieve experimental data that more closely resemble the in vivo situation, we analyzed pro-fibrotic factor expression in tumor- 
associated macrophages (TAM) directly isolated from intestinal adenomas. This approach indeed unravelled a central role of Hif1a in TAMs for the expression of various fibroblastactivating factors, e.g. COX-2, IGF-1, IL-1 $\beta$, IL-6 and granulin (Figure 5B). In our analyses, the expression of TGF- $\beta 1$, the archetypical pro-fibrotic factor, was constantly lower in Hif1adeficient TAMs, but did not reach statistical significance (Figure 5B). As the activation of TGF- $\beta$ is a complex and highly regulated process (42), we hypothesized that HIF-1 $\alpha$ is of importance in this setting. Indeed, HIF- $1 \alpha$-deficient AAMs displayed reduced levels of bioactive TGF- $\beta$ in the supernatant (Figure 5C), suggesting a functional importance of HIF$1 \alpha$ for TGF- $\beta$ activity elicited by TAMs. Next, we addressed the role of Hif1a for macrophagemediated fibroblast proliferation $(40,43)$. While conditioned medium from AAM enhanced survival of primary murine intestinal fibroblasts (MIFs), no difference between WT and Hif1anull macrophages was detectable (Figure S5B). Finally, we sought to address the secretion of pro-tumorigenic cytokines, another tumor-promoting function of TAFs (44). Stimulation of primary MIFs with conditioned medium from AAM induced gene expression of IL-6, HGF and epiregulin (Ereg), factors with established tumor-promoting activity in the intestine $(45,46)$. Of note, this effect was significantly reduced upon deletion of Hif1a in macrophages (Figure $5 D)$.

\section{Myeloid-mediated activation of TAF precursor cells depends on Hif1a}

TAFs can originate from different cellular sources, amongst others pericytes, mesenchymal stems cells (MSCs) and fibrocytes (44). We sought to investigate if macrophages are able to polarize these cell types into myofibroblasts and whether Hif1a is important in this setting. Gli1-positive pericytes, marked by tdTomato expression (47), as well as MSCs readily polarized into myofibroblasts after addition of macrophage conditioned medium (CM, Figure $6 \mathrm{~A}$ and $\mathrm{B})$. Intriguingly, HIF-1 $\alpha$ was of central importance in this setting as the effect on pericytes was completely and that on MSCs partially abolished upon Hif1a deletion. Fibrocytes are of myeloid origin, display features of monocytes as well as fibroblasts and contribute to fibrosis in various organs and tumors $(48,49)$. We took advantage of an 
Rohwer et al., HIF-1 and intestinal tumorigenesis

established protocol to generate fibrocytes ex vivo from splenic monocytes (50). Of note, Hif1a-deficient monocytes displayed greatly reduced capacity for fibrocyte production (Figure 6C). Furthermore, the expression of various tumor-supporting factors in fibrocytes was found to be regulated by Hif1a (Figure 6D). Taken together, these results point to a hitherto unknown function of Hif1a for the activation of TAF precursor cells of different origin.

\section{Non-canonical stabilization of HIF-1 $\alpha$ predominates in murine intestinal tumors}

The luminal cell layer of the colon is characterized by physiological hypoxia (51). Nuclear HIF-1 $\alpha$ protein is readily detectable in luminal enterocytes (Figure S6A), suggesting hypoxiainduced HIF-1 $\alpha$ protein stabilization in the gut under physiological conditions. Against this background, we sought to determine the relevance of hypoxia for HIF-1 $\alpha$ protein stabilization in murine intestinal tumors. Intriguingly, hypoxic areas were detected only sporadically in AOM/DSS and $\mathrm{APC}^{\mathrm{min}}$ adenomas (Figure 7A and B). This pattern of hypoxia was clearly not able to explain the pervasive stabilization of HIF-1 $\alpha$ protein in both tumor types. Against this background it is relevant to note that hypoxia-independent means of HIF-1 $\alpha$ protein stabilization have been identified and are gradually receiving more attention $(25,27)$. As activation of various oncogenes has been shown to result in hypoxia-independent HIF-1 stabilization, we decided to investigate the role of oncogenes and tumor suppressor genes characteristic for colon cancer $(27,52)$. To mimic the molecular events that instigate tumor formation in the APC ${ }^{\text {min }}$ model, mice with inducible Apc deletion were analyzed (53). Of note, acute $A p c$ loss resulted in enhanced HIF-1 $\alpha$ protein stability (Figure 7D). To analyze the role of oncogene activation for HIF-1 $\alpha$ stabilization, we took advantage of transgenic mice with inducible, epithelial-specific expression of oncogenes with relevance for CRC pathogenesis (54). The strongest effect was noted for PIK3CA ${ }^{\mathrm{H} 1047 \mathrm{R}}$, the activation of which resulted in robust HIF- $1 \alpha$ protein stabilization of the entire epithelial cell lining (Figure 7E). Activation of oncogenic KRAS or $\beta$-catenin resulted in localized HIF-1 $\alpha$ stabilization in luminal epithelial cells (Figure 7F,G,A). These results point towards a functional role of key tumor suppressors 
bioRxiv preprint doi: https://doi.org/10.1101/273045; this version posted February 28, 2018. The copyright holder for this preprint (which was not certified by peer review) is the author/funder. All rights reserved. No reuse allowed without permission.

Rohwer et al., HIF-1 and intestinal tumorigenesis

and oncogenes regulating the $\mathrm{Wnt} / \beta$-catenin, PI3K and MAPK cascades for non-canonical HIF-1 $\alpha$ stabilization during intestinal tumor formation and progression. 
Rohwer et al., HIF-1 and intestinal tumorigenesis

\section{Discussion}

Here, we addressed the functional importance of HIF-1 for colon cancer in a cell type-specific manner, using transgenic mice harbouring either an intestinal epithelial cell- (Hif1 $\mathrm{a}^{\mathrm{IEC}}$ ) or a myeloid cell-specific $\left(\right.$ Hif1 $\left.\mathrm{a}^{\mathrm{MC}}\right)$ Hif1a deletion $(21,22,26)$. We found that Hif1a plays multiple non-redundant roles in these two key cell types of intestinal tumors. Our finding of reduced tumor growth in Hif1 $\mathrm{a}^{\mathrm{IEC}}$ mice is in line with earlier reports showing Hif1a-dependent growth of human CRC xenografts $(11,12)$. Also in line with our results, the group of Celeste Simon reported that application of a chemical HIF inhibitor decreased tumor formation in mice bearing AOM/DSS adenomas and s.c. CT26 allografts (13). Of note, transgenic overexpression of oxygen-stable HIF-1 $\alpha$ in intestinal epithelial cells did not further accelerate the formation of AOM/DSS and APC ${ }^{\text {min }}$ tumors (14). Deletion of Hif1a in IECs did not affect tumor size in a chemical model of proximal colon cancer (16), arguing for the importance of cell type- and location-specific factors that need to be further investigated.

In our experiments, Hif1 $\mathrm{a}^{\mathrm{IEC}}$ mice displayed lower levels of pro-inflammatory cytokines in acute DSS-induced colitis, suggesting an activating function of HIF-1 in IECs for intestinal inflammation. This result contrasts with earlier reports from various independent groups. Karhausen et al. noted enhanced activity in hapten-induced intestinal inflammation upon conditional loss of Hif1a in IECs (51) and identified reduced barrier integrity in mutant mice as the underlying mechanism. Against this background, we determined intestinal barrier function in our mice and could not find a difference between WT and Hif1 $\mathrm{a}^{\mathrm{IEC}}$ mice (Figure S1B). Later, Shah et al. reported no effect of IEC-specific Hif1a loss on the severity of acute DSS-induced colitis (55). It is well established that the susceptibility to experimentally induced colitis is genetically determined and differs substantially between inbred strains of mice (56). Karhausen et al. and Shah et al. used mice with a mixed genetic background while our mice were $>99 \%$ C57BI6/J, potentially explaining the different results. Additional support for a protective role of HIF-1 during intestinal inflammation came from two simultaneously published seminal reports by the groups of Sean Colgan and Cormac Taylor 
Rohwer et al., HIF-1 and intestinal tumorigenesis

showing that inhibitors of prolyl hydroxylases (PHDs), a group of enzymes crucial for HIF degradation, protect against murine colitis $(57,58)$. In our opinion, different explanations are possible regarding the conflict with our data, e.g. a functional importance of other PHD targets, e.g. NF- $\kappa B$, and hydroxylase-independent functions of PHD inhibitors. Furthermore, systemically administered PHD inhibitors target every cell they encounter while in our genetic model HIF-1 was exclusively deleted in IECs, precluding a direct comparison of the different experimental approaches.

Our data support a central role of HIF- $1 \alpha$ in myeloid cells for the activation of fibroblasts in the stroma of intestinal tumors. In the context of wound healing and organ fibrosis, the importance of macrophages, especially that of alternatively activated macrophages (AAM), for fibroblast activation is well established $(59,60)$. AAMs are of special significance as they express various fibroblast-activating factors (40). While earlier reports showed a functional relevance of HIF-1 for the control of gene expression of pro-fibrotic factors (e.g. TGF- $\beta 1$, endothelin-1, fibronectin-1 and COX-2 (61-64)) in different cell types, Hif1a deletion in AAMs remained without effect on mRNA expression of a comprehensive set of pro-fibrotic factors in our experimental setup. To address the importance of the tissue context, we isolated tumorassociated macrophages (TAMs) from intestinal adenomas. Of note, in these cells the expression of various pivotal pro-fibrotic genes was indeed regulated by Hif1a. These results not only underscore the significance of Hif1a for TAM-mediated activation of TAFs, but again illustrate the importance of experimental conditions that more closely resemble the tissue context.

TAFs were for the longest time unequivocally considered to support tumor growth and progression (44). This concept was challenged by a report from the group of Raghu Kalluri, showing accelerated tumor progression upon genetic ablation of $\alpha$ smooth muscle actinpositive TAFs in murine pancreatic ductal adenocarcinoma (65). At first glance, this observation contrasts with our data arguing for a tumor-supporting role of TAFs. Besides 
Rohwer et al., HIF-1 and intestinal tumorigenesis

cancer type- and context-specific factors, the different experimental approaches are strong candidates for potential explanations. The Kalluri group used an elegantly designed genetic model resulting in direct ablation of TAFs. Our experimental setup, on the other hand, targeted TAFs indirectly via deletion of Hif1a in myeloid cells. The study by Ozdemir et al. points towards previously unappreciated tumor-inhibiting functions of TAFs. How pro- and anti-tumor aspects of TAFs are regulated is an intriguing question. While our data suggest that myeloid Hif1a impacts mainly on tumor-supporting aspects of TAFs, future work has to address the eligibility of HIF-1 inhibitors in the setting of a stroma-targeting cancer therapy.

Our study highlights that HIF- $1 \alpha$ can be stabilized by multiple means in the colon cancer context. We show that loss of APC, as well as oncogenic activation of PIK3CA or KRAS can contribute to HIF-1 $\alpha$ stabilization, even in the absence of overt hypoxia. Our findings give credence to the concept of non-canonical HIF- $1 \alpha$ stabilization that was recently coined by Amato Giaccia and colleagues (25). We have not determined the exact molecular link(s) relaying oncogenic events to HIF- $1 \alpha$ stabilization in this study. However, our data add a further layer of complexity to HIF-1 $\alpha$ regulation, and suggest that hypoxia and HIF-1 $\alpha$ stabilization can be uncoupled in cancer. 
Rohwer et al., HIF-1 and intestinal tumorigenesis

\section{Methods}

\section{Animals and Mouse models}

All mice were housed in a specific pathogen-free environment and were allowed to adapt for at least 7 days to housing conditions before starting an experiment. Mice were given tap water and standard rodent chow ad libitum and were housed at constant room temperature with a 12 hour light/dark cycle. All experiments were performed by using weight-, age- and sex-matched littermates (VillinCre/Hif1a $a^{\text {loxP/loxP }}$, VillinCre/Hif1a $a^{\text {loxP/loxP}} / \mathrm{APC}^{+/ \min }$, LysMCre/Hif1a $a^{\text {loxP/loxP }}$ and LysMCre/Hif1a $a^{\text {loxP/loxP }} / \mathrm{APC}^{+/ \min }$, all on a C57BL/6J background). For the AOM/DSS model, 6-8 week-old mice were injected intraperitoneally with $10 \mathrm{mg} / \mathrm{kg}$ AOM (azoxymethane; Sigma-Aldrich, Germany) followed by three cycles of $2 \%$ dextran sodium sulfate (DSS; MP Biomedicals, Germany) in drinking water for five days and normal drinking water for 16 days. Mice were sacrificed 8 weeks after AOM injection. Tumors were counted and measured under a dissecting microscope and colonic normal and tumor tissue snap frozen in liquid nitrogen for ex vivo analysis. In the acute DSS model, 10-12 week-old mice received 2\% DSS in the drinking water for 6 days and were sacrificed on the last day of DSS administration. In order to assess DSS colitis activity, body weight, stool consistency and the presence of occult or gross blood were determined and a scoring system was applied (66). For tumor counting in the APC ${ }^{\text {min }}$ model, mice were sacrificed at 80 days of age. The entire intestine was removed and the small intestine divided into three equal sections, with a fourth section comprising the entire large intestine. Intestinal segments were opened longitudinally and fixed at $4^{\circ} \mathrm{C}$ for $36 \mathrm{~h}$ in $10 \%$ neutral buffered formalin. Adenomas were visualized by staining with $0.1 \%$ methylene blue and counted and measured under a dissecting microscope. For histology, small intestines and colons were removed, flushed with PBS, fixed in $10 \%$ neutral buffered formalin at $4^{\circ} \mathrm{C}$ overnight and paraffin-embedded.

Mice with inducible oncogenes, transgene cassettes contain doxycycline-inducible tdTomato linked via $2 \mathrm{~A}$ peptides to human PIK3CA(H1047R), KRAS(G12V) or firefly luciferase, and a PGK promoter flanked by heterologous loxP and lox5171 sites. Transgenes were integrated 
Rohwer et al., HIF-1 and intestinal tumorigenesis

by Cre recombinase-mediated cassette exchange into a previously modified Gt(ROSA)26Sor locus harboring a promoterless neomycin resistance gene in F1 hybrid B6/129S6 embryonic stem cells. Recombined clones were selected by $250 \mu \mathrm{g} / \mathrm{ml}$ G418 and analysed by Southern blot of genomic DNA digested with BamH1 and Hindlll, using the neomycin cassette as a probe (67). Animals were generated by diploid aggregation. Transgenes were induced in vivo by administration of doxycycline $(4 \mathrm{mg} / \mathrm{ml})$ provided in a $5 \%$ sucrose solution via the drinking water. Mouse lines were inbred to C57BI6/J.

\section{FDG PET/CT}

PET (positron emission tomography) was performed longitudinally at 6 weeks after initiation of $\mathrm{AOM} / \mathrm{DSS}$ treatment in 14 mice $\left(7 \mathrm{WT}\right.$ and $7 \mathrm{Hifl}^{\mathrm{IEC}}$ ) after i.v. injection of $27.1 \pm 7.4$ MBq F-18-flurodeoxyglucose (FDG). Region of interest analysis was performed by manual lesion segmentation in the PET data co-registered to a whole-body CT (computational tomography) using the PMOD 3.4 software package (Technologies Ltd, Zürich, Switzerland). The maximum FDG uptake in the lesion was scaled to the mean FDG uptake in the thigh muscles.

\section{Metabolomics extraction}

Colon samples were homogenized in two cycles with a $20 \mathrm{~s}$ long cooling phase on ice in between by Precellyse24 (Bertin Technologies, France). Volumes of the ice-cold extraction solution methanol-chloroform-water (all Sigma, 5:2:1 v/v/v) were adjusted to the sample weight $(1 \mathrm{ml} / 50 \mathrm{mg}$ tissue). Extraction solvent contained an internal extraction standard cinnamic acid (Sigma, $2 \mu \mathrm{g} / \mathrm{ml}$ ). Colon extracts were incubated for $30 \mathrm{~min}$ at $4^{\circ} \mathrm{C}$ on a rotary wheel, and subsequently centrifuged for phase separation (15 min, maximum speed). Equal volumes of polar phase were selected from each sample separately and dried under vacuum. Extracts were stored at $-25^{\circ} \mathrm{C}$ until continuing with the preparation for GC-MS measurement. 
Rohwer et al., HIF-1 and intestinal tumorigenesis

\section{GC-MS sample preparation}

Derivatization was carried out as described with modifications (68). At first dried extracts were dissolved in $20 \mu \mathrm{l}$ of methoxyamine hydrochloride solution (Sigma, $40 \mathrm{mg} / \mathrm{ml}$ in pyridine (Roth)) and incubated for $90 \mathrm{~min}$ at $30^{\circ} \mathrm{C}$ under constant shaking. In a second phase, samples were incubated with $80 \mu \mathrm{l}$ of $\mathrm{N}$-methyl-N-[trimethylsilyl]trifluoroacetamide (MSTFA; Macherey-Nagel, Düren, Germany) at $37^{\circ} \mathrm{C}$ for $45 \mathrm{~min}$. The in-house alkane standards were added prior to the MSTFA for retention time analysis $(10 \mu \mathrm{l} / \mathrm{ml}$ MSTFA). The extracts were centrifuged for $10 \mathrm{~min}$ at $10,000 \mathrm{~g}$, aliquoted and $30 \mu \mathrm{l}$ transferred into glass vials for GC-MS measurements. Formulation of standards for retention index determination, as well as for identification and quantification of metabolites are described in (69). Identification and quantification standards were prepared in parallel with samples and in the same manner.

\section{GC-MS measurement}

Metabolite analysis was performed on a gas chromatography coupled to time of flight mass spectrometer (Pegasus III-TOF-MS-System, LECO Corp., St. Joseph, MI, USA), complemented with an auto-sampler (MultiPurpose Sampler 2 XL, Gerstel, Mülheim a.d. Ruhr, Germany). The samples and quantification standards were injected in split mode (split 1:5, injection volume $1 \mu \mathrm{l}$ ) in a temperature-controlled injector with a baffled glass liner (CAS4, Gerstel). The following temperature program was applied during sample injection: Initial temperature of $80^{\circ} \mathrm{C}$ for $30 \mathrm{~s}$ followed by a ramp with $12^{\circ} \mathrm{C} / \mathrm{min}$ to $120^{\circ} \mathrm{C}$ and a second ramp with $7^{\circ} \mathrm{C} / \mathrm{min}$ to $300^{\circ} \mathrm{C}$ and final hold for $2 \mathrm{~min}$. Gas chromatographic separation was performed on an Agilent $6890 \mathrm{~N}$ (Agilent, Santa Clara, CA, USA), equipped with a VF-5 ms column of $30-\mathrm{m}$ length, $250-\mu \mathrm{m}$ inner diameter, and $0.25-\mu \mathrm{m}$ film thickness (Varian, Palo Alto, CA, USA). Helium was applied as carrier gas with a flow rate of $1.2 \mathrm{ml} / \mathrm{min}$. Gas chromatography was performed with the temperature gradient: 2 min heating at $70^{\circ} \mathrm{C}$, first temperature gradient with $5^{\circ} \mathrm{C} / \mathrm{min}$ up to $120^{\circ} \mathrm{C}$ and hold for $30 \mathrm{~s}$; subsequently, a second temperature step of $7^{\circ} \mathrm{C} / \mathrm{min}$ up to $350^{\circ} \mathrm{C}$ with a hold time of $2 \mathrm{~min}$. The spectra were recorded in a mass range of 60 to $600 \mathrm{U}$ with 20 spectra/s at a detector voltage of $1.750 \mathrm{~V}$. 
Rohwer et al., HIF-1 and intestinal tumorigenesis

\section{GC-MS data analysis}

File processing and analysis was performed with the vendor software ChromaTOF Version 4.42 (LECO). Processing parameters: baseline offset of 1, peak width of $4 \mathrm{~s}$, signal/ noise of 20, and peak smoothing of 11 data points. Retention indices were calculated based on retention index standards. The Golm Metabolome Database (GMD) provided mass spectra and retention information for peak identification (70). Quantification of metabolites was done by external calibration as described in (69).

\section{Differentiation of murine fibrocytes}

Murine fibrocytes were cultured and differentiated as described in detail before (50). Briefly, mouse splenocytes were isolated by forcing spleens through a $100 \mu \mathrm{m}$ cell strainer (BD Biosciences, Heidelberg, Germany), collected by centrifugation (300 x g for $5 \mathrm{~min}$ ) and further purified by erythrocyte lysis. After centrifugation, CD11b-positive monocytes were enriched from spleen cells using CD11b MicroBeads (Miltenyi Biotec, Bergisch Gladbach, Germany) according to the manufacturer's protocol. Monocyte-enriched cells were resuspended in Fibrolife basal media (Lifeline Cell Technology, Frederick, USA) supplemented with 10 mM HEPES (Gibco), 2 x non-essential amino acids (Biochrom), 2 mM sodium pyruvate (Biochrom), $4 \mathrm{mM}$ glutamine (Gibco), $100 \mathrm{U} / \mathrm{ml}$ penicillin, $100 \mathrm{~g} / \mathrm{ml}$ streptomycin, 2× ITS-3 (Sigma-Aldrich) and $50 \mu \mathrm{M}$ 2-mercaptoethanol (Gibco). For fibrocyte differentiation, cells were cultured in the presence of $50 \mathrm{ng} / \mathrm{ml}$ murine IL-13 (eBioscience) and $25 \mathrm{ng} / \mathrm{ml}$ murine M-CSF (eBioscience). On day 3 of the incubation, wells were further supplemented with a cocktail containing a final concentration of $25 \mathrm{ng} / \mathrm{ml} \mathrm{IL}-13$ and 12.5 $\mathrm{ng} / \mathrm{ml} \mathrm{M-CSF}$ in fibrolife media. 5 days later, cells were fixed with $10 \%$ neutral buffered formalin and stained with hematoxylin and eosin or cell pellets were snap frozen for RNA extraction. 
Rohwer et al., HIF-1 and intestinal tumorigenesis

\section{Isolation and culture of mouse Gli1+ cells}

Gli1CreERt2 (i.e. Gli1tm3(re/ERT2)Alj/J, JAX Stock \#007913), Rosa26tdTomato (i.e. B6-CgGt(ROSA)26Sorttm(CAG-tdTomato)Hze/J, JAX Stock \#007909) were purchased from Jackson Laboratories (Bar Harbor, ME). Bigenic Gli1CreERt2;tdTomato at 8 weeks of age received tamoxifen $(3 \times 10 \mathrm{mg})$ in corn oil / $3 \%$ ethanol (Sigma) via oral gavage and were sacrificed 10 days after the last tamoxifen dose. Gli1+ bone marrow mesenchymal stem cells (MSC) were isolated from compact bone chips of femur, tibia and pelvis according to the isolation protocol by Zhu et al. (71). Gli1+ cells were grown in alpha MEM (GlutaMAX, Life Technologies) containing 20\% MSC qualified FBS (Life Technologies), $2 \%$ Penicillin Streptomycin (Life Technologies), $1 \mathrm{ng} / \mathrm{ml}$ murine basic fibroblast growth factor (Thermo Fisher Scientific) and 5ng/ml murine epidermal growth factor (Peprotech). FACS sorting was performed using the FACSAria II cell sorter (BD Biosciences) in passage 2. To study the effect of macrophage supernatant on myofibroblast differentiation of Gli1+ cells, cells were grown on coverslips (Fisher), serum starved overnight (0.5\% FBS) and treated with pure supernatant of classically or alternatively activated macrophages from wildtype or Hif1a $\mathrm{a}^{\mathrm{MC}}$ mice for 48 hours. Cells were stained with a FITC conjugated mouse anti a-SMA antibody (1:200, Sigma, \# F3777). The number of positive cells per high power field was quantified using a Keyence BZ9000 fluorescence microscope.

\section{Murine intestinal fibroblasts}

Intestinal fibroblasts were isolated from murine intestine as described in detail before (72). Briefly, intestine was detached from the mesenterium and epithelial cells were denuded by washing twice in $5 \mathrm{mM}$ EDTA/HBSS for $15 \mathrm{~min}$ followed by dispase and collagenase $\mathrm{D}$ incubation for another 30 min. Epithelial cell-denuded mucosal samples were resuspended in DMEM (Gibco) supplemented with 5\% FBS, and cultured under 5\% $\mathrm{CO}_{2}$. After one week, passaged fibroblasts survived whereas epithelial cells and macrophages underwent senescence. Cells were characterized by positive immunostaining of $\alpha$-smooth muscle actin. Intestinal fibroblasts of passage 2-5 were used for all experiments. For RNA isolation, 
150.000 cells/well were seeded in 6-well plates and cultured in DMEM supplemented with $1 \%$ FBS overnight. On the next day, cells were stimulated with macrophage-conditioned media. $24 \mathrm{~h}$ later, RNA isolation was performed using TRIzol (Invitrogen) according to the manufacturer's instructions.

\section{Culture and stimulation of small intestinal organoids and APC ${ }^{\text {min }}$ spheroids}

Based on protocols established by the Clevers group (73), a modified protocol (74) was used for crypt isolation from mouse small intestine. For organoid culture, the complete small intestine from 6-12 weeks old mice was used. Spheroid culture were grown from the distal third of the intestine from 15-20 weeks old APC ${ }^{\text {min }}$ mice. Villi were scraped off the tissue using coverslips. Tissue pieces were washed in PBS and incubated shaking in $1 \mathrm{mM}$ EDTA/PBS on ice for $30 \mathrm{~min}$ and for one further hour in $5 \mathrm{mM}$ EDTA/PBS. Subsequently, the crypt suspension was passed through a $70 \mu \mathrm{m}$ cell strainer. Following centrifugation, crypts were resuspended in Matrigel (Corning). Polymerized Matrigel drops were overlaid with ENR (Egf/noggin/R-spondin) medium. Spheroids were cultured in medium without R-spondin, containing $10 \mu \mathrm{M}$ ROCK inhibitor (Sigma). Medium was changed after 2-3 days and spheroids were no longer treated with ROCK inhibitor from this time point on. After 5-7 days incubation, organoids or spheroids were disrupted and re-seeded in Matrigel. Two days later, organoids were used for experiments, in which they were treated with $450 \mathrm{ng} / \mathrm{ml}$ LPS or 100

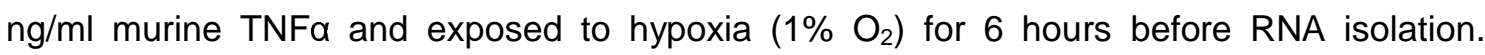
Spheroids were treated with 1:5 diluted BMDM supernatants directly after passaging and monitored for up to five days. Spheroid diameter and number were calculated by evaluation of microscopic pictures using ImageJ software.

\section{Isolation of $\mathbf{F 4 / 8 0 +}$ cells from intestinal adenomas}

Small intestinal adenomas were isolated from 120 days old $A P C^{\text {min }}$ mice. The tissue was cut into small pieces and digested with Collagenase $C$ and DNase. For further disruption, it was pulled through $18 \mathrm{G}$ and $22 \mathrm{G}$ needles. Cells were collected through a $70 \mu \mathrm{m}$ cell strainer and 
incubated in serum-containing buffer to avoid unspecific antibody binding. In the next step, cells were labeled with biotinylated anti-F4/80 antibody (BioLegend) before magnetic Streptavidin MicroBeads (Miltenyi, Bergisch Gladbach, Germany) were added. Thereafter, F4/80-positive cells were selected by magnetic separation using LS columns (Miltenyi, Bergisch Gladbach, Germany) and finally dissolved in PeqGold RNA Pure reagent (Peqlab, Erlangen, Germany) for RNA isolation.

\section{RNA extraction and quantitative PCR analysis}

Intestinal tissue was disrupted and pulverized with a TissueLyser II (Qiagen, Hilden, Germany). Total RNA was isolated using the RNeasy Mini Kit (Qiagen) and QIAshredder spin columns (Qiagen) according to the manufacturer's instructions. The yield and purity of RNA were determined spectrophotometrically. RNA integrity was checked by MOPS buffered denaturizing RNA gel electrophoresis and only samples with a $28 \mathrm{~S} / 18 \mathrm{~S}$ ratio of at least 1.8 were included in the qPCR study. First strand cDNA of 1 or $2 \mu \mathrm{g}$ total RNA/per reaction was synthesized with an oligo (dT) primer and a SuperScript ${ }^{\mathrm{TM}}$ First Strand Synthesis System (Invitrogen) according to the manufacturer's recommendations. Quantitative real-time PCR analysis was conducted on an ABI 7500 Real-Time PCR system using PowerSYBR $\circledast$ Green PCR Master Mix (Thermo Fisher Scientific, Waltham, MA USA). Primer-specific annealing temperatures were pre-evaluated prior to the study to optimize PCR conditions. Primer specificity was checked by melt-curve analyses and TAE-buffered DNA agarose gel electrophoresis of obtained PCR products. Amplification efficiency was calculated with LinRegPCR 2016.0 (Heart Failure Research Center, Amsterdam, The Netherlands) and used for efficiency corrections (75). Inter-Run calibrators were used if necessary to correct for inter-run variations. Relative fold-changes of target gene expression were calculated with qbase+ 3.0 (Biogazelle, Zwijnaarde, Belgium) that automatically applies the above mentioned corrections to the $\Delta \Delta \mathrm{Cq}$ method (76). Primers are listed in the supplemental information. 
Rohwer et al., HIF-1 and intestinal tumorigenesis

\section{Immunohistochemistry}

Immunohistochemical analysis was conducted on formalin-fixed paraffin-embedded tissues. For histopathological evaluation, intestinal sections were stained with hematoxylin and eosin and mucosal inflammation was graded as described (66). Intestinal sections were also stained with antibodies specific for F4/80 (Bio-Rad, Hemel Hempstead, UK), FSP-1 (Dako, Hamburg, Germany), HIF-1 $\alpha$ (Cayman Chemical, Ann Arbor, USA), $\alpha$ SMA (Merck Millipore, Darmstadt, Germany) and ZO-1 (Thermo Fisher Scientific, Waltham, USA). The antibodyantigen complexes were detected using biotinylated donkey anti-rat and donkey anti-rabbit secondary antibodies (Dianova, Hamburg, Germany) and the Dako REAL Detection System (Dako). Sections were counterstained with hematoxylin. Immunohistochemical detection of HIF-1a was performed as previously described (77). For the immunohistochemical assessment of hypoxic areas, the Hypoxyprobe-1 Kit (Hypoxyprobe Inc., Burlington, USA) was used as described before (78). Tumor-associated macrophage abundance was determined by quantification of $\mathrm{F} 4 / 80+$ cells in at least 5 random fields of view.

\section{Multiplex immunohistochemistry}

Paraffin sections were deparaffinized and rehydrated according to standard protocols. Subsequently, the sections were fixed by 10 min incubation in $3.5 \%$ formalin. Antigen retrieval was achieved by 15 min cooking at $110^{\circ} \mathrm{C}$ in Dako target retrieval solution using the Decloaking Chamber (Biocare Medical). After 10 min blocking in Dako antibody diluent, the sections were incubated with anti-HIF-1a (Cayman Chemical, 1:20.000 in Dako antibody diluent) for $30 \mathrm{~min}$ and afterwards treated with ImmPRESS anti-rabbit IgG (Vector) for 20 min. To permanently label Hif1a with a fluorescent tag, sections were treated with Opal 520 (Opal 4-color IHC kit, PerkinElmer, 1:50 in provided amplification reagent) for $10 \mathrm{~min}$. Subsequently, the antibodies were removed from sections by microwave treatment in AR6 buffer (Opal 4-color IHC kit, PerkinElmer), while the bound Opal fluorophore outlasted this procedure. For additional staining of Hypoxyprobe (pimonidazole adducts), the sections were incubated with mouse IgG block (M.O.M. detection kit, Vector) over night at $4^{\circ} \mathrm{C}$. At the next 
Rohwer et al., HIF-1 and intestinal tumorigenesis

day, anti-pimonidazole mouse IgG (hpi, 1:200 in 1:10-diluted protein concentrate from M.O.M. kit) was added to the sections for $30 \mathrm{~min}$. Thereafter, sections were first incubated with ImmPRESS mouse IgG (Vector) for 20 min and then treated with Opal 670 (Opal 4-color IHC kit, PerkinElmer, 1:50 in provided amplification reagent) for $10 \mathrm{~min}$. After repeated microwave treatment, nuclei were stained with spectral DAPI (Opal 4-color IHC kit, PerkinElmer) for $5 \mathrm{~min}$. Coverslips were mounted on the stained tissue sections using Vectashield HardSet mounting medium (Vector). Fluorescent signals were detected, separated and recorded using the Vectra 3.0 multiplex imaging system (PerkinElmer).

\section{Isolation and stimulation of bone marrow-derived macrophages (BMDM)}

Bone marrow was collected from tibiae, femurs and humeri of 8-12 weeks old wildtype and Hif1 $\mathrm{a}^{\mathrm{MC}}$ mice. After flushing out the marrow, red blood cells were lysed with ACK buffer and cells were seeded on plastic plates in RPMI supplemented with $10 \% \mathrm{FBS}, 100 \mathrm{U} / \mathrm{ml}$ penicillin, $100 \mu \mathrm{g} / \mathrm{ml}$ streptomycin. Next day, non-attached cells were collected and cultured in RPMI supplemented with 20\% FBS and 30\% L929-conditioned medium for one week. Differentiated BMDMs were stimulated for $48 \mathrm{~h}$ with LPS (100 ng/ml, Sigma Aldrich) and $\gamma-$ IFN $(20 \mathrm{ng} / \mathrm{ml})$ for classically activated (CAM) and with IL-4 (20 ng/ml, both from eBioscience) for alternatively activated macrophages (AAM). For RNA isolation, cells were harvested using TRIzol (Invitrogen) from MO (non-polarized), CAM and AAM. To collect conditioned media from polarized macrophages, cells were extensively washed with PBS 48 $\mathrm{h}$ after stimulation and fresh media was added for an additional $24 \mathrm{~h}$.

\section{Flow cytometric analyses of murine leukocyte populations}

Small intestine was rinsed thoroughly and incubated in buffer containing EDTA to remove the mucus. Cells were minced and digested with type IV collagenase (Cellsystems). Blood was taken from the right ventricle. Small intestine, blood, bone marrow, and spleen cells were subjected to red blood cell lysis using Pharm Lyse (BD Biosciences, San Jose, USA). Flow cytometric analysis was done as described in detail before (79). Antibodies were purchased 
Rohwer et al., HIF-1 and intestinal tumorigenesis

from eBioscience (CD45, CD11b, Ly6G, F4/80, CD3, CD4, CD8, CD103, and NK1.1), BD Biosciences (Gr1, I- $\left.A^{b}\right)$, and Biolegend (CD11c).

\section{Statistics}

Statistical analysis was done using Prism 4.0 software (GraphPad Software, San Diego, California, USA). Statistical significance was determined by two-tailed Student's $t$ test for unpaired or paired observations. Differences were considered statistically significant at $p<0.05$. Data are expressed as means + SEM. The asterisks in the graphs indicate statistically significant changes with $p$ values: ${ }^{*} p<0.05,{ }^{* *} p \leq 0.01$ and ${ }^{* *} p \leq 0.001$.

\section{Study approval}

Experimentation and transgenic animal generation was approved by authorities in Berlin (Landesamt für Gesundheit und Soziales: G0004/07, G0185/09, G0143/14). 
Rohwer et al., HIF-1 and intestinal tumorigenesis

\section{Author Contributions}

Conceptualization, N.R., M.M. and T.C.; Methodology, N.R., M.E., S.J., A.E., K.T.W., A.A.K., A.F., S.N., M.G., I.R., T.E., C.Z., S.K., R.H., M.B.M., W.F. and M.M.; Formal Analysis, Investigation, and Visualization, N.R., M.E., S.J., A.E., A.A.K., R.K., S.N., I.R., M.G., C.Z., S.K., M.B.M., M.M. and T.C.; Writing, N.R., F.T., M.M. and T.C.; Supervision, Resources, and Funding Acquisition, R.K., S.K., C.E.L., W.B., M.S., L.S., O.S., F.T., M.M. and T.C.; Project Administration, T.C.

\section{Acknowledgements}

Research in the Cramer lab was supported by grants from Deutsche Krebshilfe (109160) and Deutsche Forschungsgemeinschaft (CR 133/2-1 until 2-4). Nadine Rohwer was supported by a grant from the BMBF (MAPTor-NET (031A426A)). We are indebted to Deborah Gumucio (University of Michigan, USA) for providing Villin-Cre mice. We are grateful to Christine Sers (Charité, Berlin) and Florian R. Greten (Georg-Speyer-Haus, Frankfurt) for helpful discussions and to Ilia N. Buhtoiarov (Children's Hospital, Cleveland, USA), Glenn S. Belinsky, Daniel W. Rosenberg (University of Connecticut Health Center, Farmington, USA) and Takuji Tanaka (Gifu Municipal Hospital, Japan) for providing control reagents. We very much appreciate the help of Ralf Weiskirchen (RWTH University Hospital Aachen) with the MLEC assay. The excellent technical assistance of Birgit Bogdanoff and Simone Spiekermann is highly appreciated. 
Rohwer et al., HIF-1 and intestinal tumorigenesis

\section{References}

1. Siegel RL, Miller KD, Fedewa SA, Ahnen DJ, Meester RGS, Barzi A, and Jemal A. Colorectal cancer statistics, 2017. CA: A Cancer Journal for Clinicians. 2017;67(3):177-93.

2. Brenner H, Kloor M, and Pox CP. Colorectal cancer. Lancet (London, England). 2014;383(9927):1490-502.

3. Huang M, Shen A, Ding J, and Geng M. Molecularly targeted cancer therapy: some lessons from the past decade. Trends in pharmacological sciences. 2014;35(1):41-50.

4. Mazumdar J, Dondeti V, and Simon MC. Hypoxia-inducible factors in stem cells and cancer. Journal of cellular and molecular medicine. 2009;13(11-12):4319-28.

5. Harris AL. Hypoxia--a key regulatory factor in tumour growth. Nature reviews Cancer. 2002;2(1):38-47.

6. Maxwell PH, Pugh CW, and Ratcliffe PJ. Activation of the HIF pathway in cancer. Current opinion in genetics \& development. 2001;11(3):293-9.

7. Carmeliet P, Dor Y, Herbert JM, Fukumura D, Brusselmans K, Dewerchin M, Neeman M, Bono F, Abramovitch R, Maxwell P, et al. Role of HIF-1alpha in hypoxia-mediated apoptosis, cell proliferation and tumour angiogenesis. Nature. 1998;394(6692):485-90.

8. Yoshimura H, Dhar DK, Kohno H, Kubota H, Fujii T, Ueda S, Kinugasa S, Tachibana $\mathrm{M}$, and Nagasue N. Prognostic impact of hypoxia-inducible factors 1alpha and 2alpha in colorectal cancer patients: correlation with tumor angiogenesis and cyclooxygenase-2 expression. ClinCancer Res. 2004;10(24):8554-60.

9. Zhong H, De Marzo AM, Laughner E, Lim M, Hilton DA, Zagzag D, Buechler P, Isaacs WB, Semenza GL, and Simons JW. Overexpression of hypoxia-inducible factor 1alpha in common human cancers and their metastases. Cancer Res. 1999;59(22):5830-5.

10. Talks KL, Turley H, Gatter KC, Maxwell PH, Pugh CW, Ratcliffe PJ, and Harris AL. The expression and distribution of the hypoxia-inducible factors HIF-1alpha and HIF2alpha in normal human tissues, cancers, and tumor-associated macrophages. The American journal of pathology. 2000;157(2):411-21.

11. Imamura T, Kikuchi H, Herraiz MT, Park DY, Mizukami Y, Mino-Kenduson M, Lynch MP, Rueda BR, Benita Y, Xavier RJ, et al. HIF-1alpha and HIF-2alpha have divergent roles in colon cancer. International journal of cancer Journal international du cancer. 2009;124(4):763-71.

12. Mizukami Y, Jo WS, Duerr EM, Gala M, Li J, Zhang X, Zimmer MA, Iliopoulos O, Zukerberg LR, Kohgo Y, et al. Induction of interleukin-8 preserves the angiogenic response in HIF-1alpha-deficient colon cancer cells. Nature medicine. 2005;11(9):992-7.

13. Shay JE, Imtiyaz HZ, Sivanand S, Durham AC, Skuli N, Hsu S, Mucaj V, EisingerMathason TS, Krock BL, Giannoukos DN, et al. Inhibition of hypoxia-inducible factors limits tumor progression in a mouse model of colorectal cancer.

Carcinogenesis. 2014;35(5):1067-77.

14. Xue X, Ramakrishnan SK, and Shah YM. Activation of HIF-1alpha does not increase intestinal tumorigenesis. American journal of physiology Gastrointestinal and liver physiology. 2014;307(2):G187-95.

15. Xue X, Ramakrishnan S, Anderson E, Taylor M, Zimmermann EM, Spence JR, Huang S, Greenson JK, and Shah YM. Endothelial PAS domain protein 1 activates the inflammatory response in the intestinal epithelium to promote colitis in mice. Gastroenterology. 2013;145(4):831-41. 
16. Mladenova DN, Dahlstrom JE, Tran PN, Benthani F, Bean EG, Ng I, Pangon L, Currey N, and Kohonen-Corish MR. HIFlalpha deficiency reduces inflammation in a mouse model of proximal colon cancer. Disease models \& mechanisms. 2015;8(9):1093-103.

17. Semenza GL. Hypoxia-inducible factors: mediators of cancer progression and targets for cancer therapy. Trends in pharmacological sciences. 2012;33(4):207-14.

18. Stockmann C, Doedens A, Weidemann A, Zhang N, Takeda N, Greenberg JI, Cheresh DA, and Johnson RS. Deletion of vascular endothelial growth factor in myeloid cells accelerates tumorigenesis. Nature. 2008;456(7223):814-8.

19. Kim JW, Evans C, Weidemann A, Takeda N, Lee YS, Stockmann C, Branco-Price C, Brandberg F, Leone G, Ostrowski MC, et al. Loss of fibroblast HIF-1alpha accelerates tumorigenesis. Cancer research. 2012;72(13):3187-95.

20. Palazon A, Tyrakis PA, Macias D, Velica P, Rundqvist H, Fitzpatrick S, Vojnovic N, Phan AT, Loman N, Hedenfalk I, et al. An HIF-1alpha/VEGF-A Axis in Cytotoxic T Cells Regulates Tumor Progression. Cancer cell. 2017;32(5):669-83.e5.

21. Cramer T, Yamanishi Y, Clausen BE, Forster I, Pawlinski R, Mackman N, Haase VH, Jaenisch R, Corr M, Nizet V, et al. HIF-1alpha is essential for myeloid cell-mediated inflammation. Cell. 2003;112(5):645-57.

22. Ryan HE, Poloni M, McNulty W, Elson D, Gassmann M, Arbeit JM, and Johnson RS. Hypoxia-inducible factor-1alpha is a positive factor in solid tumor growth. Cancer research. 2000;60(15):4010-5.

23. Okayasu I, Ohkusa T, Kajiura K, Kanno J, and Sakamoto S. Promotion of colorectal neoplasia in experimental murine ulcerative colitis. Gut. 1996;39(1):87-92.

24. Su LK, Kinzler KW, Vogelstein B, Preisinger AC, Moser AR, Luongo C, Gould KA, and Dove WF. Multiple intestinal neoplasia caused by a mutation in the murine homolog of the APC gene. Science (New York, NY). 1992;256(5057):668-70.

25. LaGory EL, and Giaccia AJ. The ever-expanding role of HIF in tumour and stromal biology. Nature cell biology. 2016;18(4):356-65.

26. Madison BB, Dunbar L, Qiao XT, Braunstein K, Braunstein E, and Gumucio DL. Cis elements of the villin gene control expression in restricted domains of the vertical (crypt) and horizontal (duodenum, cecum) axes of the intestine. The Journal of biological chemistry. 2002;277(36):33275-83.

27. Semenza GL. HIF-1 mediates metabolic responses to intratumoral hypoxia and oncogenic mutations. The Journal of clinical investigation. 2013;123(9):3664-71.

28. Janakiram NB, and Rao CV. The role of inflammation in colon cancer. Advances in experimental medicine and biology. 2014;816(25-52.

29. Biswas SK, Allavena P, and Mantovani A. Tumor-associated macrophages: functional diversity, clinical significance, and open questions. Seminars in immunopathology. 2013;35(5):585-600.

30. Palazon A, Goldrath AW, Nizet V, and Johnson RS. HIF transcription factors, inflammation, and immunity. Immunity. 2014;41(4):518-28.

31. Trottier MD, Irwin R, Li Y, McCabe LR, and Fraker PJ. Enhanced production of early lineages of monocytic and granulocytic cells in mice with colitis. Proceedings of the National Academy of Sciences of the United States of America. 2012;109(41):16594-9.

32. Mantovani A, and Sica A. Macrophages, innate immunity and cancer: balance, tolerance, and diversity. Current opinion in immunology. 2010;22(2):231-7.

33. Mitchem JB, Brennan DJ, Knolhoff BL, Belt BA, Zhu Y, Sanford DE, Belaygorod L, Carpenter D, Collins L, Piwnica-Worms D, et al. Targeting tumor-infiltrating macrophages decreases tumor-initiating cells, relieves immunosuppression, and improves chemotherapeutic responses. Cancer research. 2013;73(3):1128-41. 
34. Ricci-Vitiani L, Lombardi DG, Pilozzi E, Biffoni M, Todaro M, Peschle C, and De Maria R. Identification and expansion of human colon-cancer-initiating cells. Nature. 2007;445(7123):111-5.

35. Barker N, van Es JH, Kuipers J, Kujala P, van den Born M, Cozijnsen M, Haegebarth A, Korving J, Begthel H, Peters PJ, et al. Identification of stem cells in small intestine and colon by marker gene Lgr5. Nature. 2007;449(7165):1003-7.

36. Ragusa S, Cheng J, Ivanov KI, Zangger N, Ceteci F, Bernier-Latmani J, Milatos S, Joseph JM, Tercier S, Bouzourene H, et al. PROX1 promotes metabolic adaptation and fuels outgrowth of Wnt(high) metastatic colon cancer cells. Cell reports. 2014;8(6):1957-73.

37. Heijmans J, Buller NV, Muncan V, and van den Brink GR. Role of mast cells in colorectal cancer development, the jury is still out. Biochimica et biophysica acta. 2012;1822(1):9-13.

38. Isella C, Terrasi A, Bellomo SE, Petti C, Galatola G, Muratore A, Mellano A, Senetta $\mathrm{R}$, Cassenti A, Sonetto C, et al. Stromal contribution to the colorectal cancer transcriptome. 2015;47(4):312-9.

39. Calon A, Lonardo E, Berenguer-Llergo A, Espinet E, Hernando-Momblona X, Iglesias M, Sevillano M, Palomo-Ponce S, and Tauriello DV. Stromal gene expression defines poor-prognosis subtypes in colorectal cancer. 2015;47(4):320-9.

40. Wynn TA, and Vannella KM. Macrophages in Tissue Repair, Regeneration, and Fibrosis. Immunity. 2016;44(3):450-62.

41. Ross R, and Benditt EP. Wound healing and collagen formation. I. Sequential changes in components of guinea pig skin wounds observed in the electron microscope. The Journal of biophysical and biochemical cytology. 1961;11(677-700.

42. Travis MA, and Sheppard D. TGF-beta activation and function in immunity. Annual review of immunology. 2014;32(51-82.

43. Pradere JP, Kluwe J, De Minicis S, Jiao JJ, Gwak GY, Dapito DH, Jang MK, Guenther ND, Mederacke I, Friedman R, et al. Hepatic macrophages but not dendritic cells contribute to liver fibrosis by promoting the survival of activated hepatic stellate cells in mice. Hepatology (Baltimore, Md). 2013;58(4):1461-73.

44. Gascard P, and Tlsty TD. Carcinoma-associated fibroblasts: orchestrating the composition of malignancy. Genes \& development. 2016;30(9):1002-19.

45. Waldner MJ, Foersch S, and Neurath MF. Interleukin-6--a key regulator of colorectal cancer development. International journal of biological sciences. 2012;8(9):1248-53.

46. Neufert C, Becker C, Tureci O, Waldner MJ, Backert I, Floh K, Atreya I, Leppkes M, Jefremow A, Vieth M, et al. Tumor fibroblast-derived epiregulin promotes growth of colitis-associated neoplasms through ERK. The Journal of clinical investigation. 2013;123(4):1428-43.

47. Kramann R, Schneider RK, DiRocco DP, Machado F, Fleig S, Bondzie PA, Henderson JM, Ebert BL, and Humphreys BD. Perivascular Gli1+ progenitors are key contributors to injury-induced organ fibrosis. Cell stem cell. 2015;16(1):51-66.

48. Bucala R, Spiegel LA, Chesney J, Hogan M, and Cerami A. Circulating fibrocytes define a new leukocyte subpopulation that mediates tissue repair. Molecular medicine (Cambridge, Mass). 1994;1(1):71-81.

49. Raffaghello L, and Dazzi F. Classification and biology of tumour associated stromal cells. Immunology letters. 2015;168(2):175-82.

50. Crawford JR, Pilling D, and Gomer RH. Improved serum-free culture conditions for spleen-derived murine fibrocytes. Journal of immunological methods. 2010;363(1):920. 
51. Karhausen J, Furuta GT, Tomaszewski JE, Johnson RS, Colgan SP, and Haase VH. Epithelial hypoxia-inducible factor-1 is protective in murine experimental colitis. The Journal of clinical investigation. 2004;114(8):1098-106.

52. Vogelstein B, and Kinzler KW. Cancer genes and the pathways they control. Nature medicine. 2004;10(8):789-99.

53. Sansom OJ, Reed KR, Hayes AJ, Ireland H, Brinkmann H, Newton IP, Batlle E, Simon-Assmann P, Clevers H, Nathke IS, et al. Loss of Apc in vivo immediately perturbs Wnt signaling, differentiation, and migration. Genes \& development. 2004;18(12):1385-90.

54. Riemer P, Rydenfelt M, Marks M, van Eunen K, Thedieck K, Herrmann BG, Blüthgen N, Sers C, and Morkel M. Oncogenic $\beta$-catenin and PIK3CA instruct network states and cancer phenotypes in intestinal organoids. The Journal of cell biology. 2017.

55. Shah YM, Ito S, Morimura K, Chen C, Yim SH, Haase VH, and Gonzalez FJ. Hypoxia-inducible factor augments experimental colitis through an MIF-dependent inflammatory signaling cascade. Gastroenterology. 2008;134(7):2036-48, 48.e1-3.

56. Mahler M, Bristol IJ, Leiter EH, Workman AE, Birkenmeier EH, Elson CO, and Sundberg JP. Differential susceptibility of inbred mouse strains to dextran sulfate sodium-induced colitis. The American journal of physiology. 1998;274(3 Pt 1):G54451.

57. Cummins EP, Seeballuck F, Keely SJ, Mangan NE, Callanan JJ, Fallon PG, and Taylor CT. The hydroxylase inhibitor dimethyloxalylglycine is protective in a murine model of colitis. Gastroenterology. 2008;134(1):156-65.

58. Robinson A, Keely S, Karhausen J, Gerich ME, Furuta GT, and Colgan SP. Mucosal protection by hypoxia-inducible factor prolyl hydroxylase inhibition.

Gastroenterology. 2008;134(1):145-55.

59. Wynn TA, and Barron L. Macrophages: master regulators of inflammation and fibrosis. Seminars in liver disease. 2010;30(3):245-57.

60. Xue J, Sharma V, Hsieh MH, Chawla A, Murali R, Pandol SJ, and Habtezion A. Alternatively activated macrophages promote pancreatic fibrosis in chronic pancreatitis. Nature communications. 2015;6(7158.

61. Krishnamachary B, Berg-Dixon S, Kelly B, Agani F, Feldser D, Ferreira G, Iyer N, LaRusch J, Pak B, Taghavi P, et al. Regulation of colon carcinoma cell invasion by hypoxia-inducible factor 1. Cancer research. 2003;63(5):1138-43.

62. Kaidi A, Qualtrough D, Williams AC, and Paraskeva C. Direct transcriptional upregulation of cyclooxygenase-2 by hypoxia-inducible factor (HIF)-1 promotes colorectal tumor cell survival and enhances HIF-1 transcriptional activity during hypoxia. Cancer research. 2006;66(13):6683-91.

63. Hung SP, Yang MH, Tseng KF, and Lee OK. Hypoxia-induced secretion of TGFbeta1 in mesenchymal stem cell promotes breast cancer cell progression. Cell transplantation. 2013;22(10):1869-82.

64. Hu J, Discher DJ, Bishopric NH, and Webster KA. Hypoxia regulates expression of the endothelin-1 gene through a proximal hypoxia-inducible factor-1 binding site on the antisense strand. Biochemical and biophysical research communications. 1998;245(3):894-9.

65. Ozdemir BC, Pentcheva-Hoang T, Carstens JL, Zheng X, Wu CC, Simpson TR, Laklai H, Sugimoto H, Kahlert C, Novitskiy SV, et al. Depletion of carcinomaassociated fibroblasts and fibrosis induces immunosuppression and accelerates pancreas cancer with reduced survival. Cancer cell. 2014;25(6):719-34.

66. Erben U, Loddenkemper C, Doerfel K, Spieckermann S, Haller D, Heimesaat MM, Zeitz M, Siegmund B, and Kuhl AA. A guide to histomorphological evaluation of 
intestinal inflammation in mouse models. International journal of clinical and experimental pathology. 2014;7(8):4557-76.

67. Vidigal JA, Morkel M, Wittler L, Brouwer-Lehmitz A, Grote P, Macura K, and Herrmann BG. An inducible RNA interference system for the functional dissection of mouse embryogenesis. Nucleic acids research. 2010;38(11):e122.

68. Kempa S, Hummel J, Schwemmer T, Pietzke M, Strehmel N, Wienkoop S, Kopka J, and Weckwerth W. An automated GCxGC-TOF-MS protocol for batch-wise extraction and alignment of mass isotopomer matrixes from differential 13C-labelling experiments: a case study for photoautotrophic-mixotrophic grown Chlamydomonas reinhardtii cells. Journal of basic microbiology. 2009;49(1):82-91.

69. Pietzke M, Zasada C, Mudrich S, and Kempa S. Decoding the dynamics of cellular metabolism and the action of 3-bromopyruvate and 2-deoxyglucose using pulsed stable isotope-resolved metabolomics. Cancer \& metabolism. 2014;2(9.

70. Kopka J, Schauer N, Krueger S, Birkemeyer C, Usadel B, Bergmuller E, Dormann P, Weckwerth W, Gibon Y, Stitt M, et al. GMD@CSB.DB: the Golm Metabolome Database. Bioinformatics (Oxford, England). 2005;21(8):1635-8.

71. Zhu H, Guo Z-K, Jiang X-X, Li H, Wang X-Y, Yao H-Y, Zhang Y, and Mao N. A protocol for isolation and culture of mesenchymal stem cells from mouse compact bone. Nat Protocols. 2010;5(3):550-60.

72. Khalil H, Nie W, Edwards RA, and Yoo J. Isolation of primary myofibroblasts from mouse and human colon tissue. Journal of visualized experiments : JoVE. 201380).

73. Sato T, Vries RG, Snippert HJ, van de Wetering M, Barker N, Stange DE, van Es JH, Abo A, Kujala P, Peters PJ, et al. Single Lgr5 stem cells build crypt-villus structures in vitro without a mesenchymal niche. Nature. 2009;459(7244):262-5.

74. Andersson-Rolf A, Fink J, Mustata RC, and Koo BK. A video protocol of retroviral infection in primary intestinal organoid culture. J Vis Exp. 201490):e51765.

75. Ramakers C, Ruijter JM, Deprez RH, and Moorman AF. Assumption-free analysis of quantitative real-time polymerase chain reaction (PCR) data. Neuroscience letters. 2003;339(1):62-6.

76. Pfaffl MW. A new mathematical model for relative quantification in real-time RTPCR. Nucleic acids research. 2001;29(9):e45.

77. Rohwer N, Lobitz S, Daskalow K, Jons T, Vieth M, Schlag PM, Kemmner W, Wiedenmann B, Cramer T, and Hocker M. HIF-1alpha determines the metastatic potential of gastric cancer cells. British journal of cancer. 2009;100(5):772-81.

78. Daskalow K, Rohwer N, Raskopf E, Dupuy E, Kuhl A, Loddenkemper C, Wiedenmann B, Schmitz V, and Cramer T. Role of hypoxia-inducible transcription factor 1alpha for progression and chemosensitivity of murine hepatocellular carcinoma. Journal of molecular medicine (Berlin, Germany). 2010;88(8):817-27.

79. Hammerich L, Warzecha KT, Stefkova M, Bartneck M, Ohl K, Gassler N, Luedde T, Trautwein C, Tenbrock K, and Tacke F. Cyclic adenosine monophosphate-responsive element modulator alpha overexpression impairs function of hepatic myeloid-derived suppressor cells and aggravates immune-mediated hepatitis in mice. Hepatology (Baltimore, Md). 2015;61(3):990-1002. 
Rohwer et al., HIF-1 and intestinal tumorigenesis

Figures and Figure Legends

Figure 1. HIF-1 $\alpha$ in IECs controls intestinal tumor formation, wnt/ $\beta$-catenin activity and glucose metabolism. (A) Tumor number and size of WT and Hif1a ${ }^{\mathrm{IEC}}$ mice in the AOM/DSS (left, $n=4-6$ per group) and APC ${ }^{\text {min }}$ model (right, $n=7$ per group). (B) Relative mRNA expression of wnt/ $\beta$-catenin target genes in colon tumors of WT and Hif $1 \mathrm{a}^{\mathrm{IEC}}$ mice following AOM/DSS treatment, $n=3$ per group. (C) RNA in-situ hybridization of the wnt/ $\beta$-catenin target gene Axin2 in AOM/DSS adenomas of WT and Hif1 $\mathrm{a}^{\mathrm{IEC}}$ mice. (D) Relative mRNA expression of wnt/ $\beta$-catenin target genes in WT and Hif1 $\mathrm{a}^{\mathrm{IEC}}$ APC ${ }^{\mathrm{min}}$ tumors, $n=3$ per group. (E) Glucose levels (left) and FDG-PET/CT analysis (right) of AOM/DSS-induced colon tumors (white arrow) of WT $(n=5)$ and Hif1 $1 \mathrm{a}^{\mathrm{IEC}}(n=8)$ mice. (F) Metabolization of glucose into lactate (left, $n=3-5$ per group) and citrate (right, $n=13$ per group) in colon tumors of WT and Hif1a $\mathrm{a}^{\mathrm{IEC}}$ mice following AOM/DSS treatment determined by stable isotope-resolved metabolomics. Data are represented as mean + SEM. ${ }^{*} \mathrm{p}<0.05 ;{ }^{* *} \mathrm{p}<0.01$ by unpaired Student's t test.

Figure 2. IEC-specific deletion of Hif1a reduces intestinal inflammation. (A) Body weight change of WT and Hif1a $\mathrm{a}^{\mathrm{IEC}}$ mice following AOM/DSS treatment ( $n=14$ per group), (B) disease activity index ( $n=4-5$ per group), (C) relative mRNA expression of inflammatory genes in colon tissues ( $n=3$ per group) and (D) secretion of cytokines by colonic explants of WT and Hif1a ${ }^{\mathrm{IEC}}$ mice on day 6 of acute DSS treatment ( $n=4-5$ per group). (E) Proinflammatory cytokine mRNA expression in small intestinal organoids from WT and Hif1a $a^{\text {IEC }}$ mice ( $n=3$ per group). Shown are mean and standard deviation of technical duplicates from one representative experiment. Unless indicated otherwise, data are represented as mean + SEM. ${ }^{*} p<0.05 ;{ }^{* *} p<0.01 ;{ }^{* * *} p<0.001$ by unpaired Student's t test.

Figure 3. Hif1a in myeloid cells controls intestinal tumor formation without affecting inflammation. (A) Tumor number and size in WT and Hif1 $\mathrm{a}^{\mathrm{MC}}$ mice after AOM/DSS 
administration (left, $n=3$ per group) and in the APC ${ }^{\text {Min }}$ model (right, $n=4$ per group). (B) Body weight change of WT $(n=7)$ and Hif1 $\mathrm{a}^{\mathrm{MC}}(n=8)$ mice following AOM/DSS treatment. (C) Disease activity index ( $n=5-6$ per group), (D) Relative mRNA expression of inflammatory genes in colon tissues ( $n=3$ per group) and (E) Secretion of cytokines by colonic explants of WT and Hif $1 \mathrm{a}^{\mathrm{MC}}$ mice on day 6 of acute DSS treatment ( $n=5$ per group). (F) Relative mRNA expression of inflammatory genes in intestinal tissues of WT and Hif1 $\mathrm{a}^{\mathrm{MC}}$ control $(n=3-4$ per group) and $\operatorname{APC}^{\text {min }}\left(n=7-8\right.$ per group) mice. Data are represented as mean $+\mathrm{SEM} .{ }^{*} \mathrm{p}<0.05$; ${ }^{* *} p<0.01$ by unpaired Student's $t$ test.

Figure 4. Tumoral abundance of macrophages and stimulation of adenoma growth ex vivo is not affected by loss of Hif1a. (A) Representative F4/80 stainings of intestinal sections obtained from AOM/DSS-treated (above) and APC $^{\text {min }}$ (below) WT and Hif1a ${ }^{\text {MC }}$ mice. Right, quantification of F4/80-positive cells ( $n=6$ per group). (B) Total leukocytes were isolated from small intestines of wildtype and Hif $1 \mathrm{a}^{\mathrm{MC}}$ mice remaining either untreated or bearing APC $^{\text {min }}$ adenomas and analyzed by flow cytometry ( $n=4$ per group). Relative numbers of different subtypes are shown. Flow cytometric analyses of the CD11cmacrophage subset (I-Ab+, CD11c-, CD11b+, CD103-, F4/80+), the CD11c+ macrophage subset $(\mathrm{I}-\mathrm{Ab}+, \mathrm{CD} 11 \mathrm{c}+, \mathrm{CD} 11 \mathrm{~b}+, \mathrm{CD} 103-, \mathrm{F} 4 / 80+)$ and the CD11b+ dendritic cell subset (I$\mathrm{Ab}+, \mathrm{CD11}+, \mathrm{CD11b}+, \mathrm{CD103+}, \mathrm{F} 4 / 80-)$ were performed. Lymphoid leukocytes of the small intestine were subdivided into T cells (CD4+, CD8+) and NK cells (CD4-, NK1.1+). (C) Effect of macrophage conditioned media (CM) on spheroid formation from APC ${ }^{\text {min }}$ adenomas. Left, representative image of spheroids after stimulation. Quantification of spheroid number (middle) and diameter (right) after stimulation with conditioned media from WT and Hif1a-KO macrophages ( $n=3$ per group). Data in $\mathbf{A}$ and $\mathbf{B}$ are represented as mean + SEM. ${ }^{*} p<0.05$ by unpaired Student's t test. C right shows mean \pm SD.

Figure 5. Hif1a in myeloid cells is essential for activation and pro-tumorigenic gene expression of intestinal fibroblasts. (A) Immunohistochemical analysis of myofibroblast 
markers $\alpha$ SMA and FSP-1 in intestinal sections from AOM/DSS-treated (above) and APC ${ }^{\text {min }}$ (below) WT and Hif1a ${ }^{\mathrm{MC}}$ mice. (B) Relative mRNA expression of pro-fibrotic genes in tumorassociated macrophages isolated from $\mathrm{APC}^{\mathrm{min}}$ adenomas from WT $(n=2)$ and Hif1a $\mathrm{a}^{\mathrm{MC}}(n=$ 4) mice. (C) Determination of bioactive TGF- $\beta$ in the supernatant of WT and alternatively activated Hif1a-KO macrophages ( $n=3$ per group). (D) Relative mRNA expression of protumorigenic genes in primary murine intestinal fibroblasts stimulated with conditioned media from WT and Hif1a-KO macrophages ( $n=3$ per group). Data are represented as mean + SEM. ${ }^{*} p<0.05,{ }^{* *} p<0.01$ by unpaired Student's $t$ test.

Figure 6. Myeloid cell-mediated activation of TAF precursor cells depends on Hif1a. (A) Representative images and quantification of $\mathrm{Gli}^{+} \mathrm{MSC}$ isolated from bone-chips of bigenic Gli1CreER ${ }^{\mathrm{t} 2}$;tdTomato mice and cultured with supernatants of CAM or AAM from either wildtype or Hif1 $\mathrm{a}^{\mathrm{MC}}$ mice and stained for alpha smooth muscle actin (aSMA) indicating myofibroblast differentiation ( $n=3$ per group). (B) Mesenchymal stem cells were cultured in collagen gels for 14 days either in stem cell expansion medium (SCEM, control) or in a mixture of SCEM and supernatants of MO, CAM or AAM ( $n=3$ per group). Collagen gel areas were measured using the ImageJ software. (C) Representative images of fibrocytes differentiated in vitro from splenic monocytes from WT and and Hif1 $\mathrm{a}^{\mathrm{MC}}$ mice. Magnification 25x (upper panel) and 100x (lower panel). (D) Relative mRNA expression of selected protumorigenic factors in differentiated fibrocytes from WT and and Hif1 $\mathrm{a}^{\mathrm{MC}}$ mice $(n=3$ per group). Data are represented as mean + SEM. * $p<0.05$ by unpaired Student's $t$ test.

Figure 7. Non-canonical stabilization of HIF-1 $\alpha$ in murine intestine. (A) Immunofluorescent analysis of hypoxyprobe (red) and HIF-1 $\alpha$ (green) in AOM/DSS-induced (left) and APC ${ }^{\text {min }}$ (right) adenomas. (B) Analysis of relative number of cells in adenomas expressing either hypoxyprobe (HP) or HIF-1 $\alpha$. (C-G) Immunohistochemical staining of HIF1a in intestinal sections from mice with inducible expression of firefly luciferase (C, luc), inducible loss of APC (D), PIK3CA (E), KRAS (F) or oncogenic $\beta$-catenin (CTNNB1, G). Data 
bioRxiv preprint doi: https://doi.org/10.1101/273045; this version posted February 28, 2018. The copyright holder for this preprint (which was not certified by peer review) is the author/funder. All rights reserved. No reuse allowed without permission.

Rohwer et al., HIF-1 and intestinal tumorigenesis

in $B$ show mean $+S D, 7-8$ adenomas from 2 animals per model were evaluated. ${ }^{* *} p<0.001$

by unpaired Student's $t$ test. 
A AOM/DSS

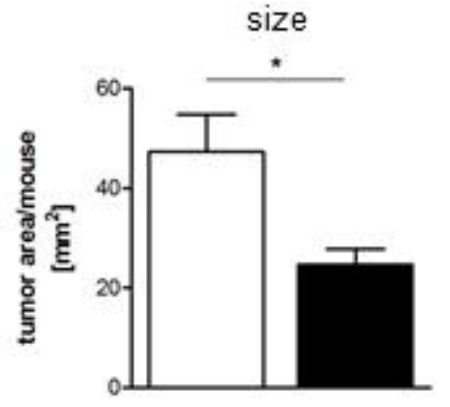

B

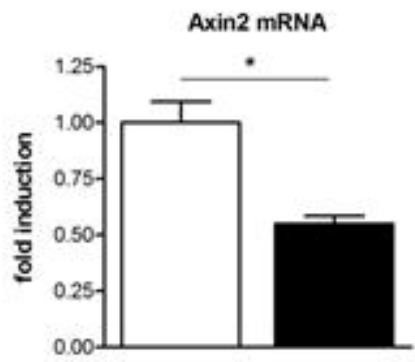

D
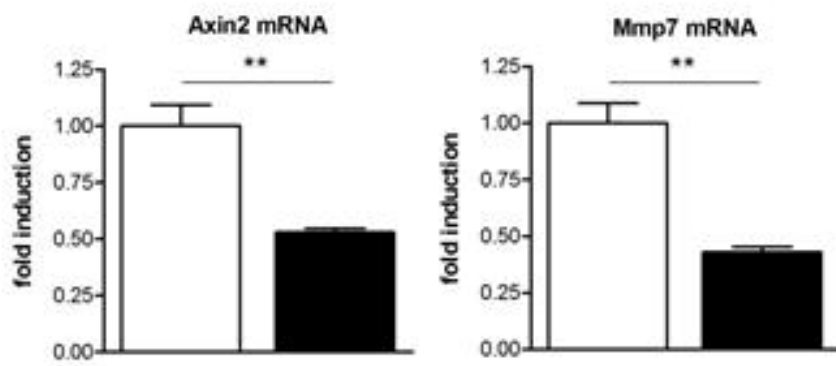

E

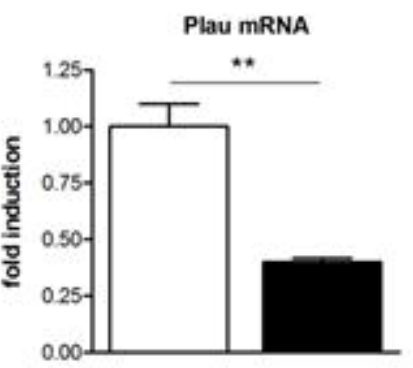

\section{APC min}

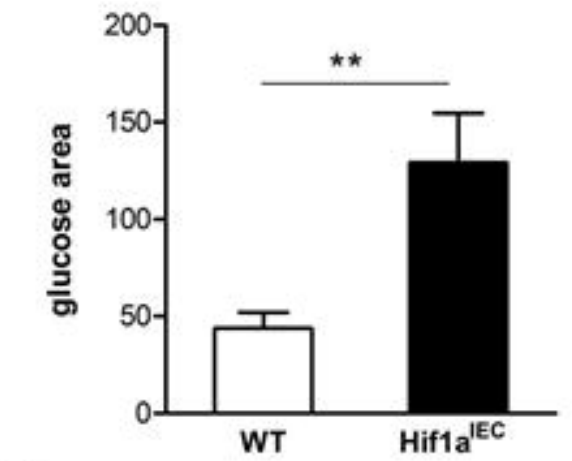

F

glucose

lactic acid

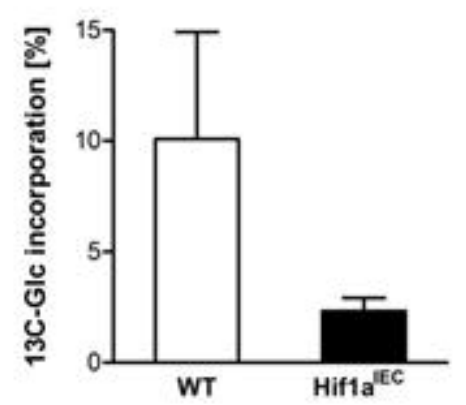

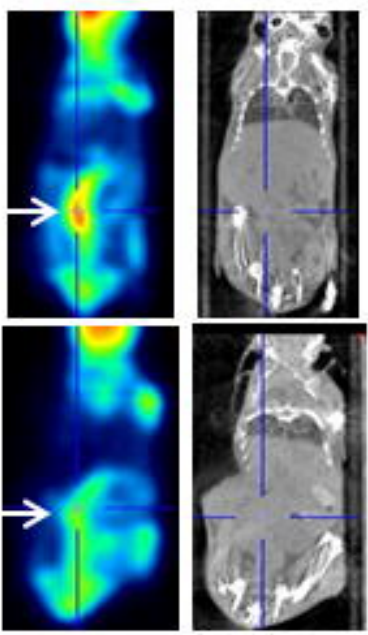

citric acid

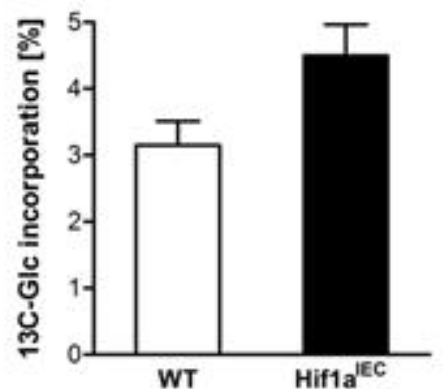

APC ${ }^{\text {min }}$

Figure 1

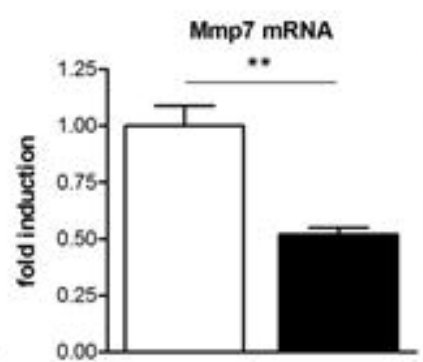

size
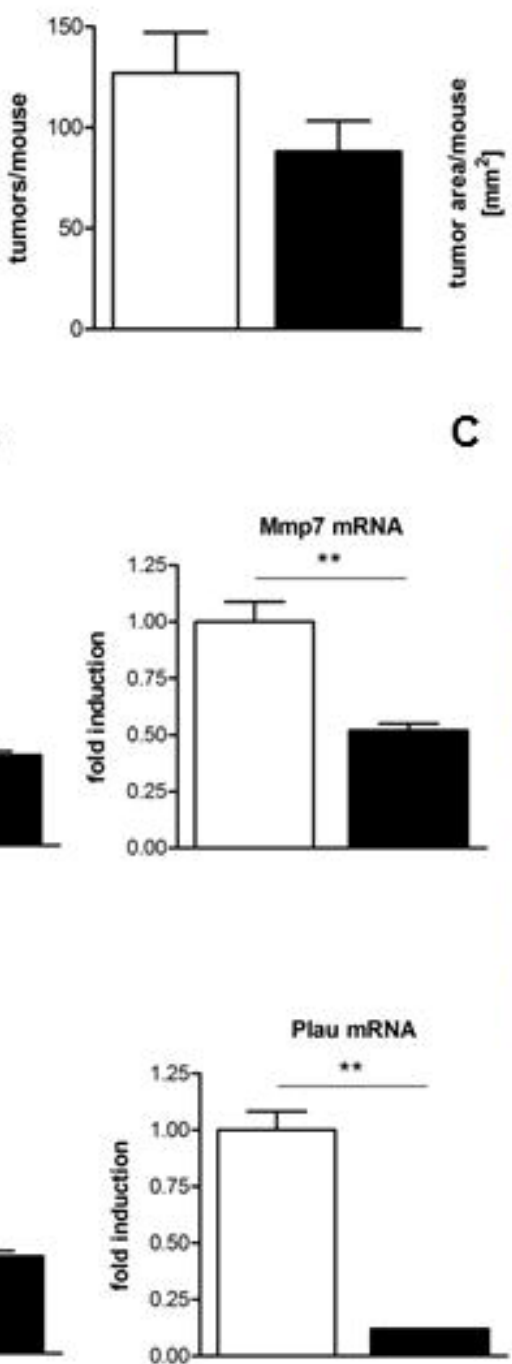

C
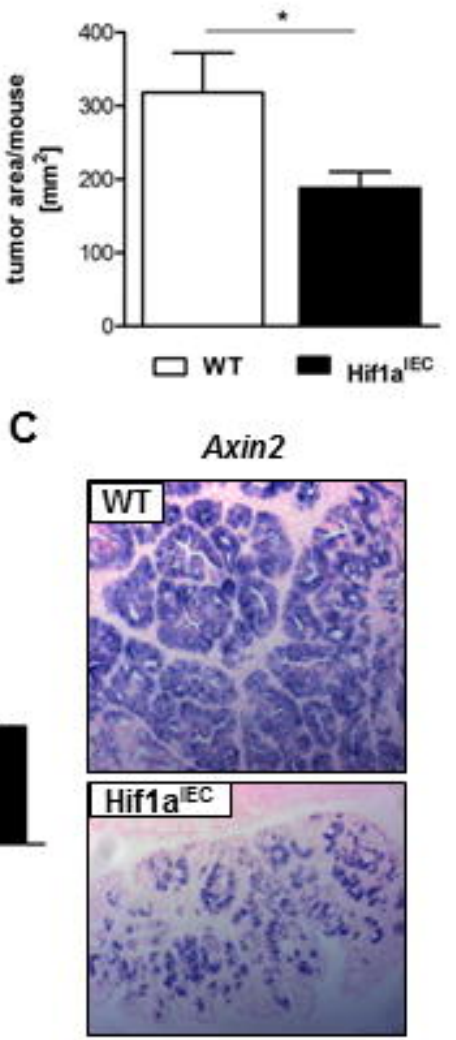

$\square$ WT
Hif1a

WT

Hif1 $a^{\text {IEC }}$ 
A

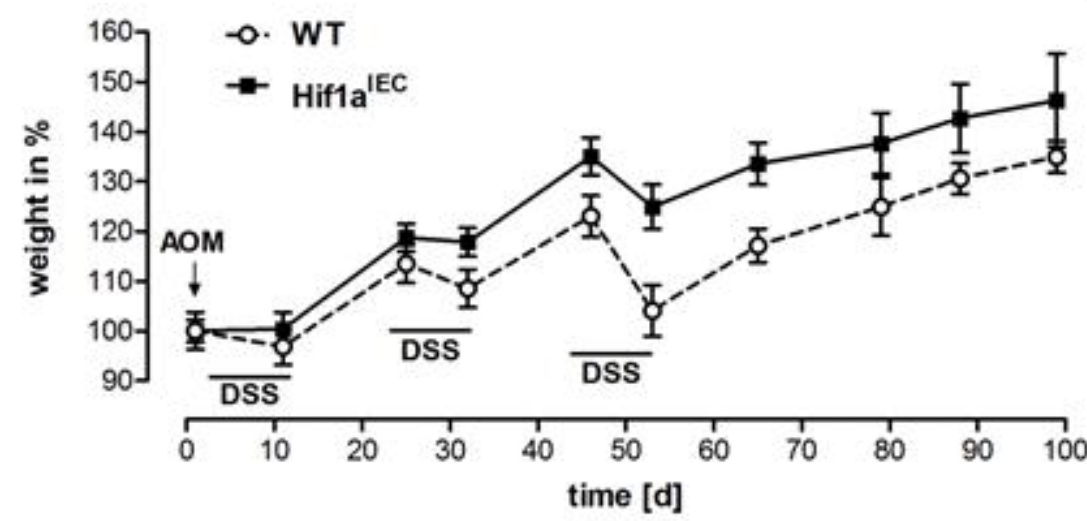

C

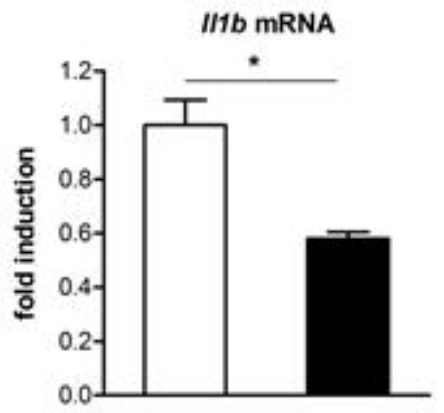

D

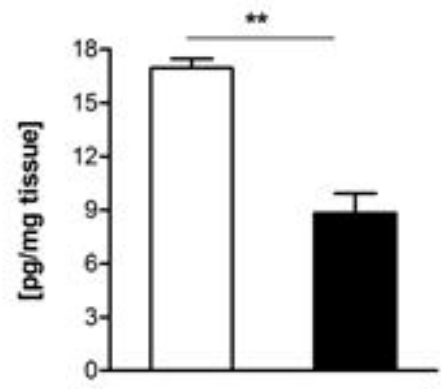

E

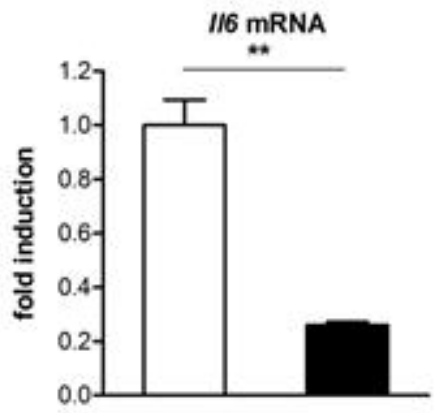

small intestinal organoids

॥6 mRNA

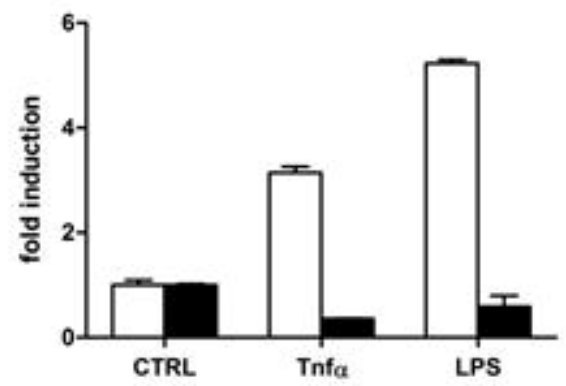

B
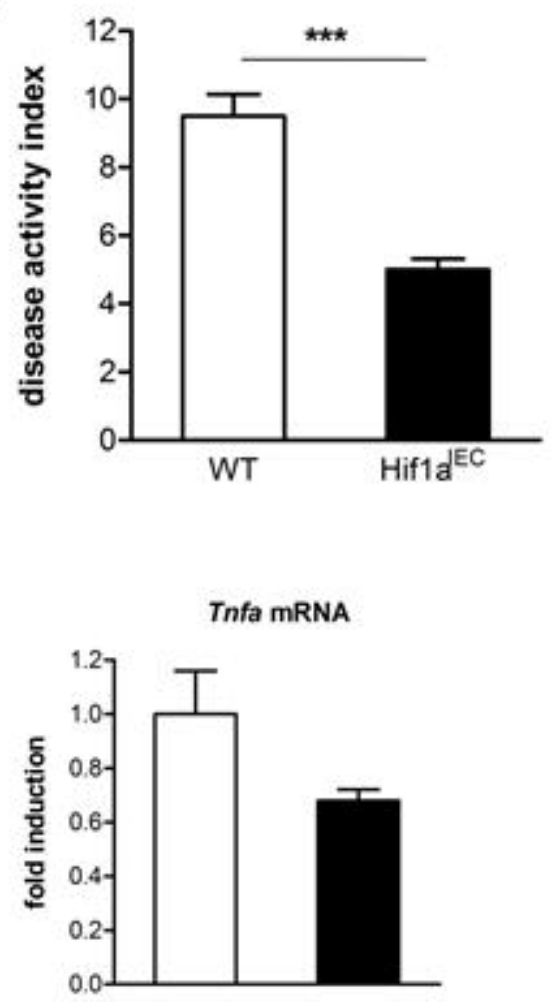

TNF- $\alpha$ protein

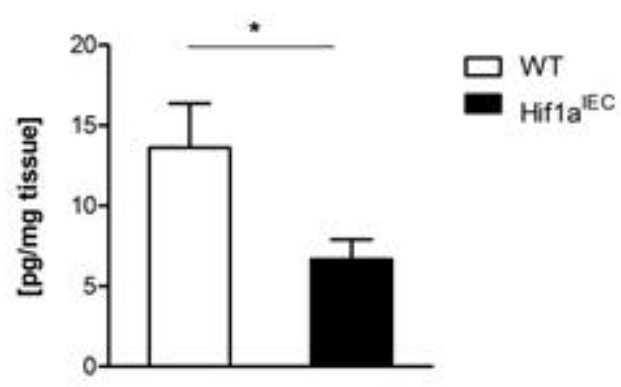

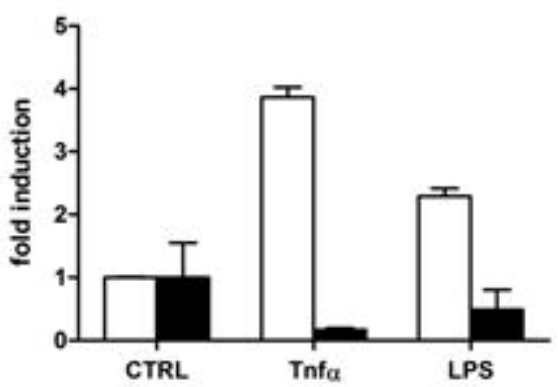

Cxc/5 mRNA

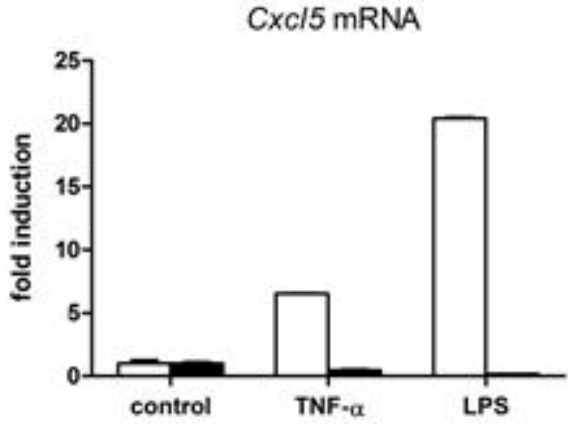

$\square$ WT 
A not certified by peer review) is the author/funder. All rights reserved. No reuse allowed without permission.

Figure 3

\section{AOM/DSS}
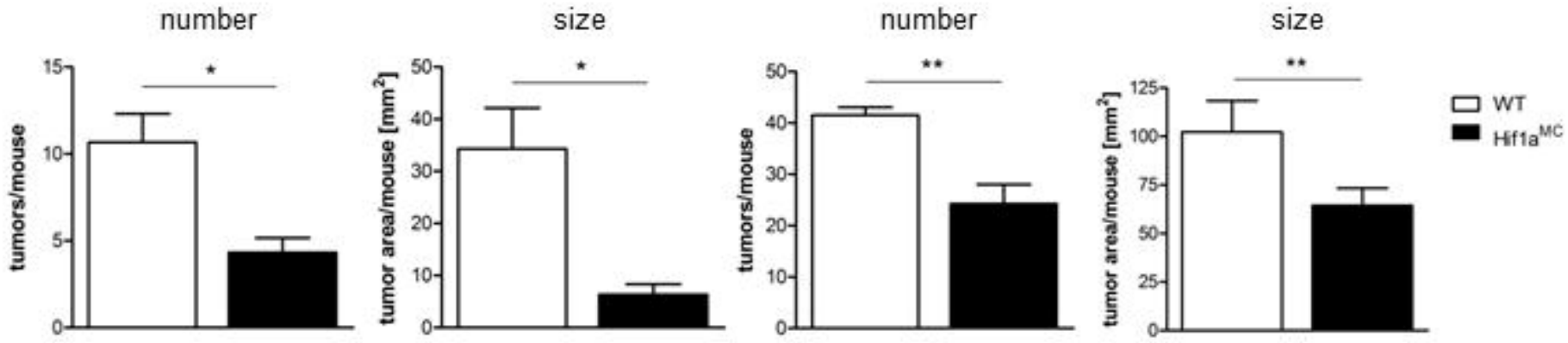

B
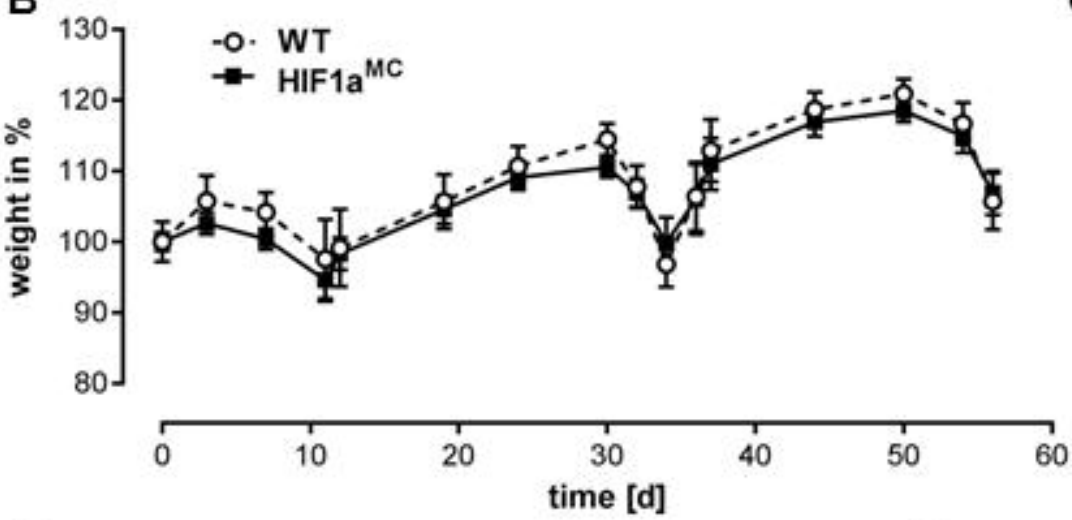

C

E
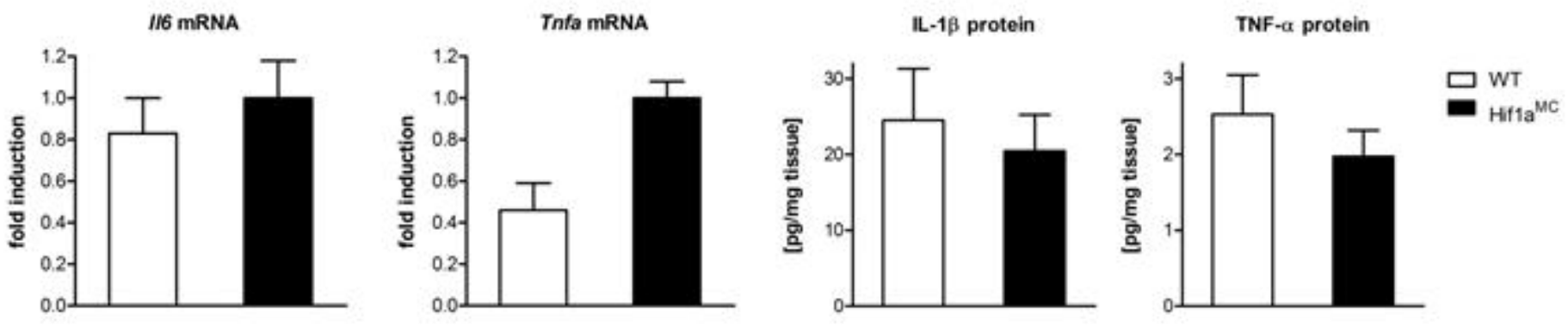

F

116 mRNA

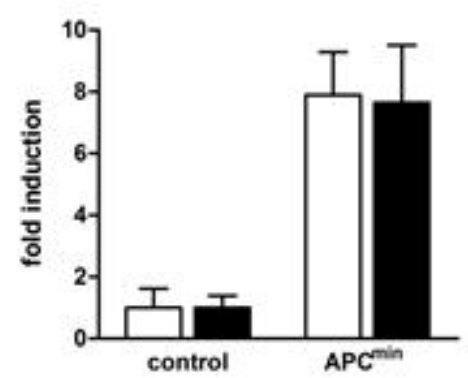

IIb MRNA

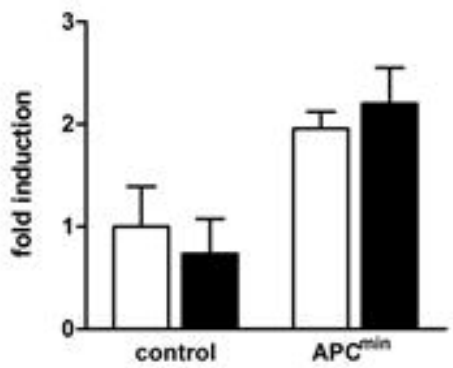

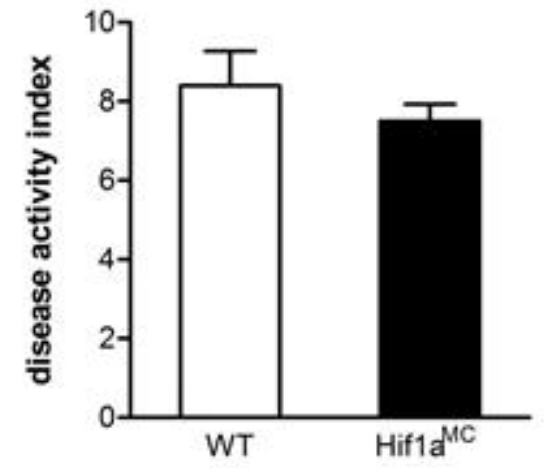


A not certified by peer review) is the author/funder. All rights reserved. No reuse allowed without permission

WT
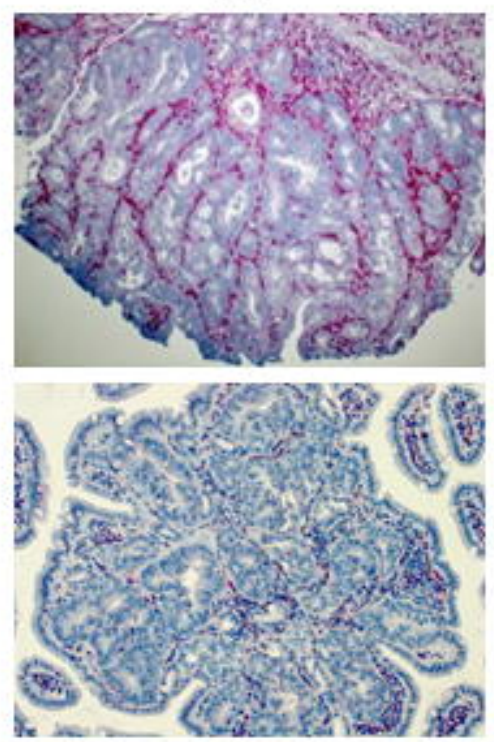

AOM

DSS

$\mathrm{APC}^{\mathrm{min}}$
Hif1 $\mathrm{a}^{\mathrm{MC}}$
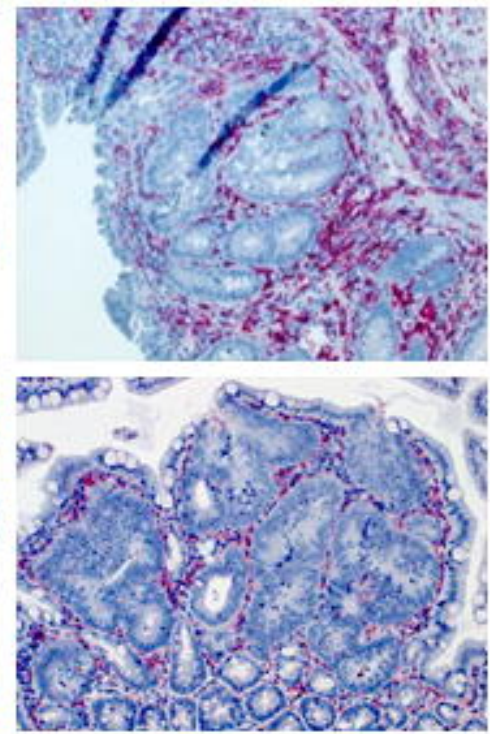

AOM/DSS
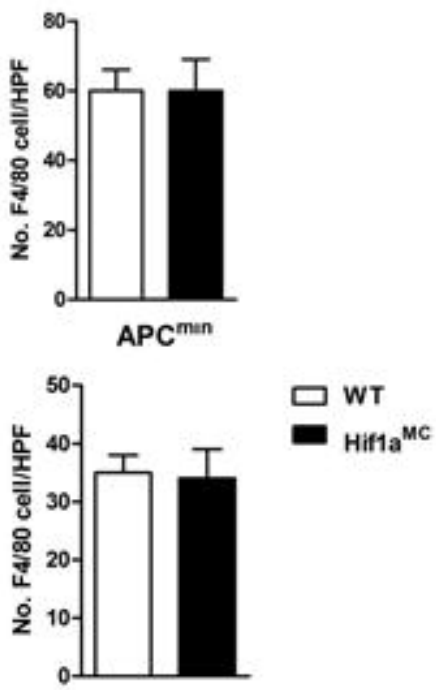

B

CD11c-macrophages

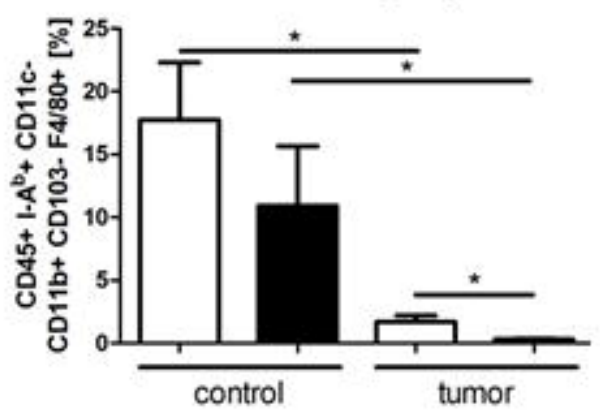

CD4+ T cells

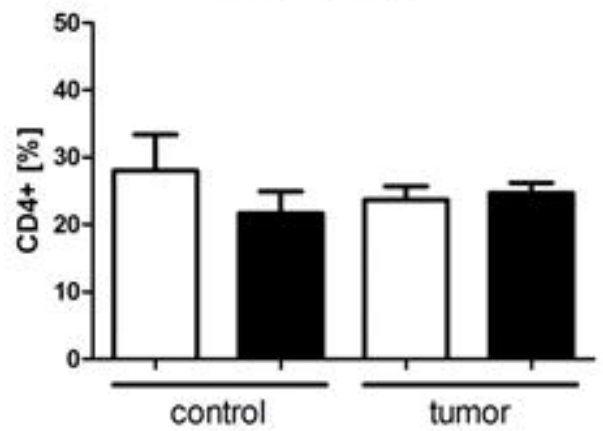

C

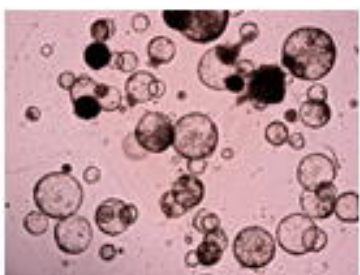

WT (CM)
CD11c+ macrophages

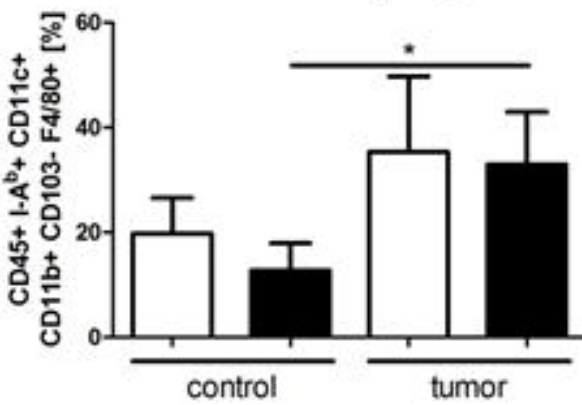

CD8+ T cells
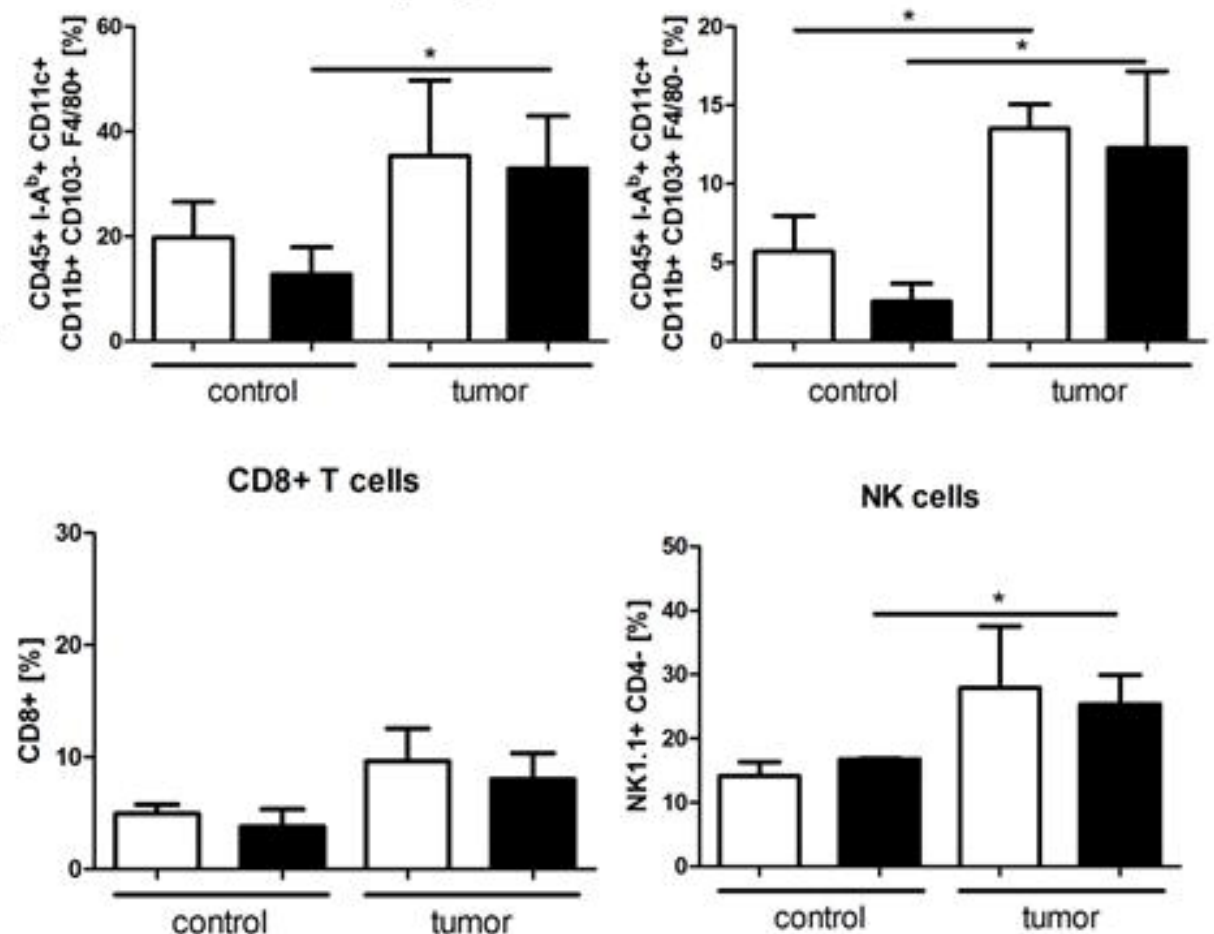

NK cells

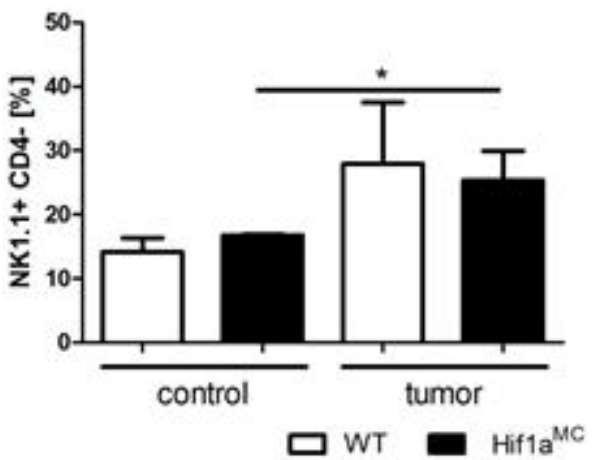

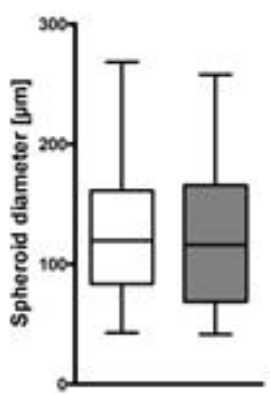

口 wT (CM)

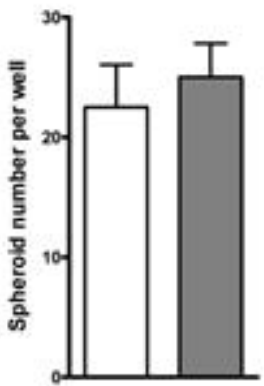

\section{$\square$ Hirta KO (CM)}



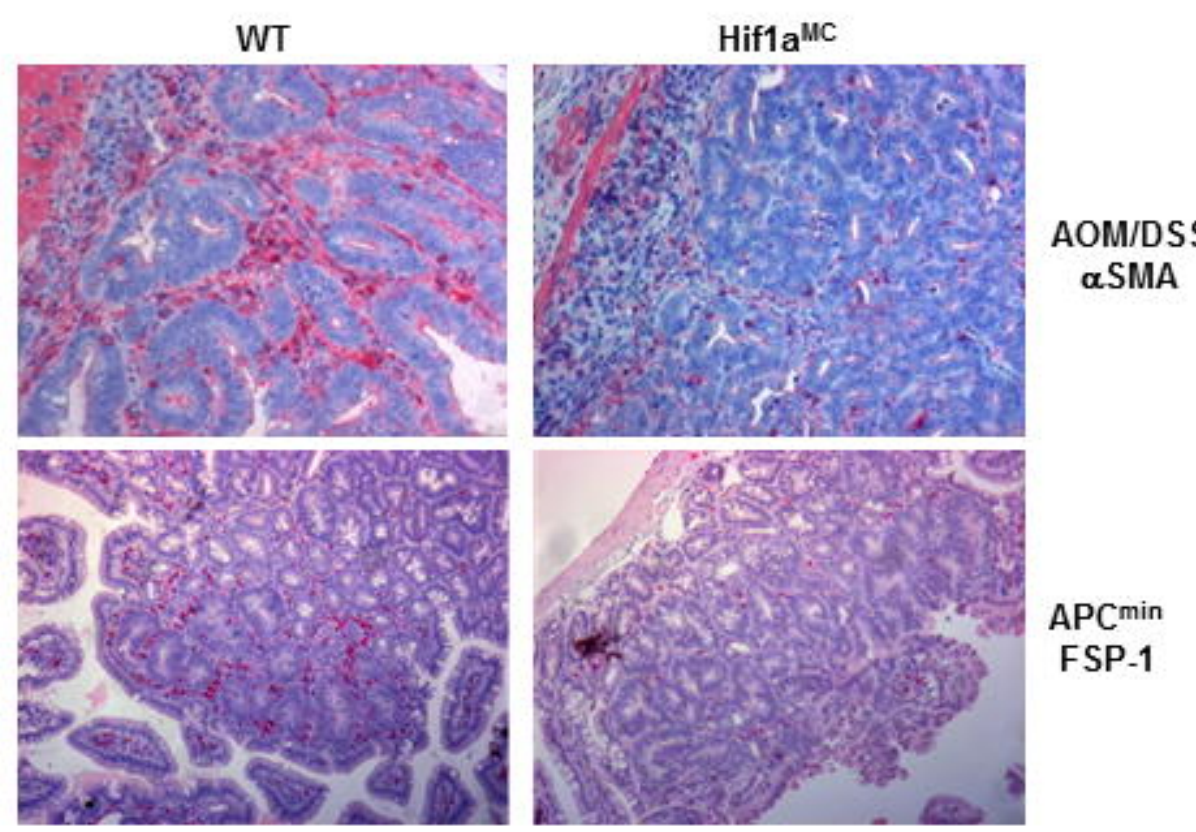

B
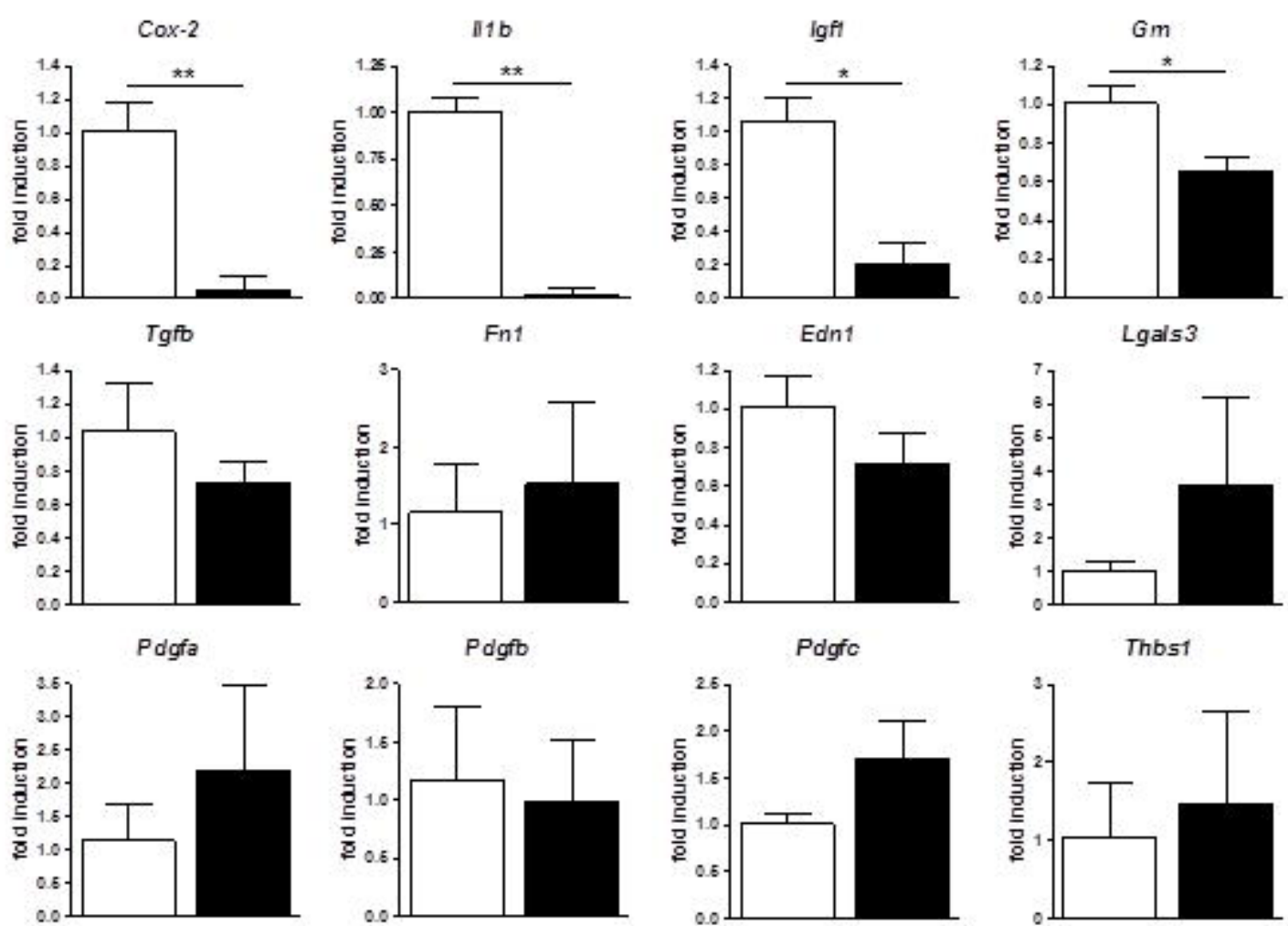

Pdgfo

Polgfe

$\square$ WT

Hiffako

C
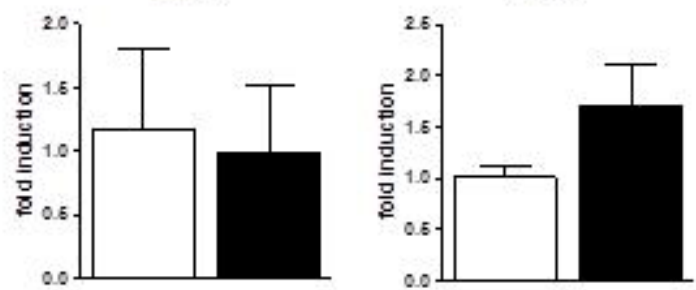

Thbs1
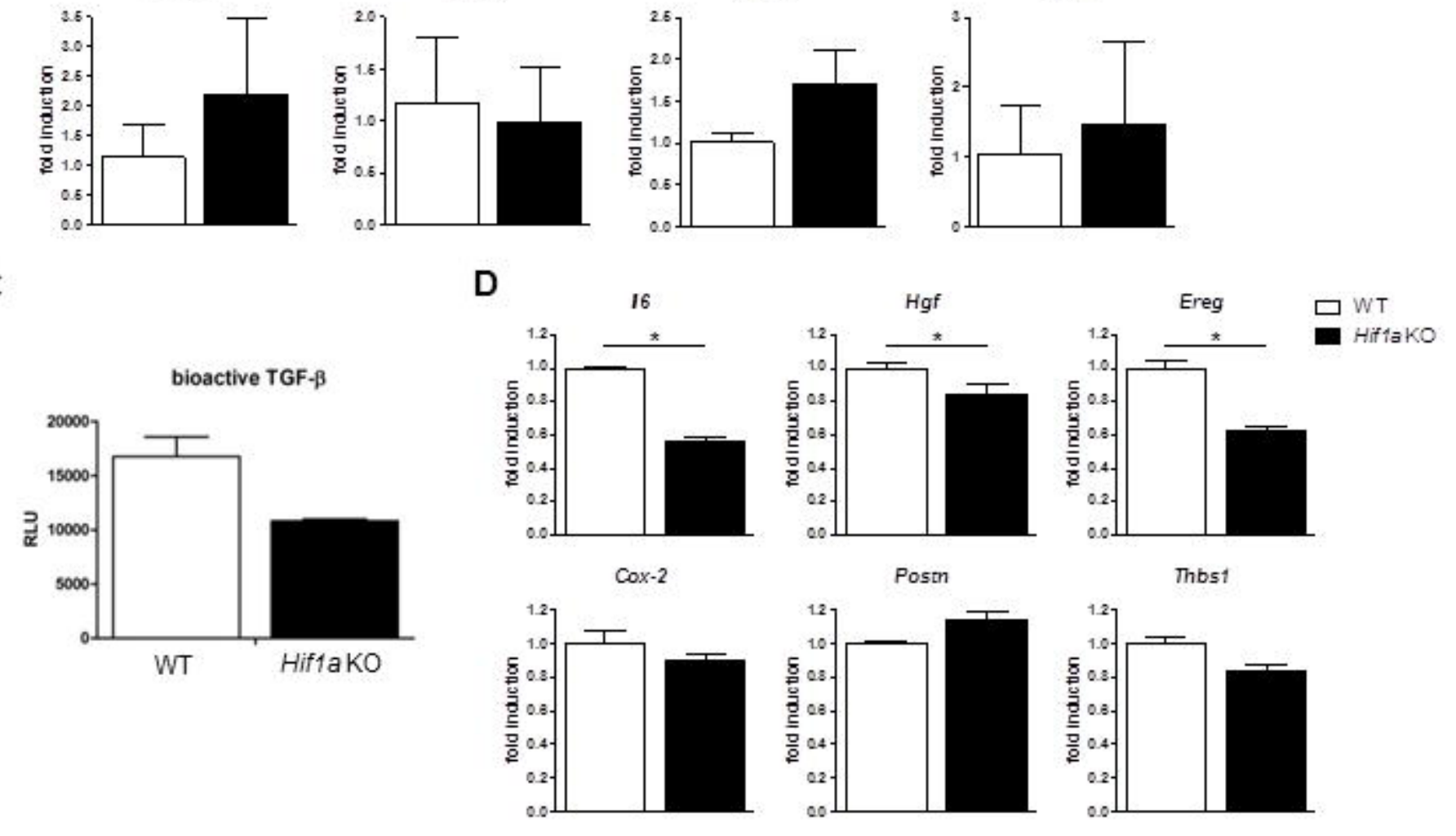
A

tdTomato

a-SMA

merged+DAPI

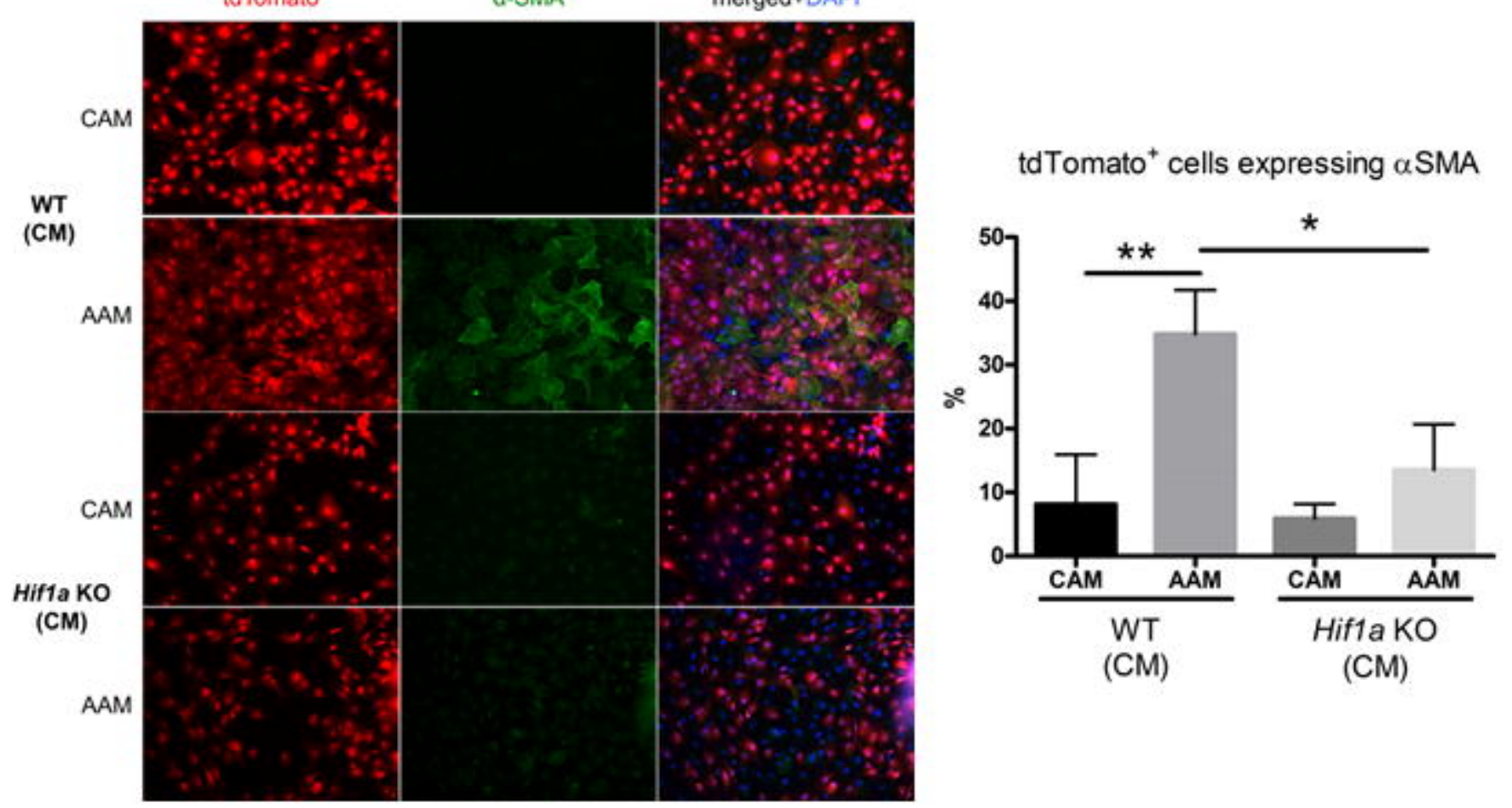

B

C

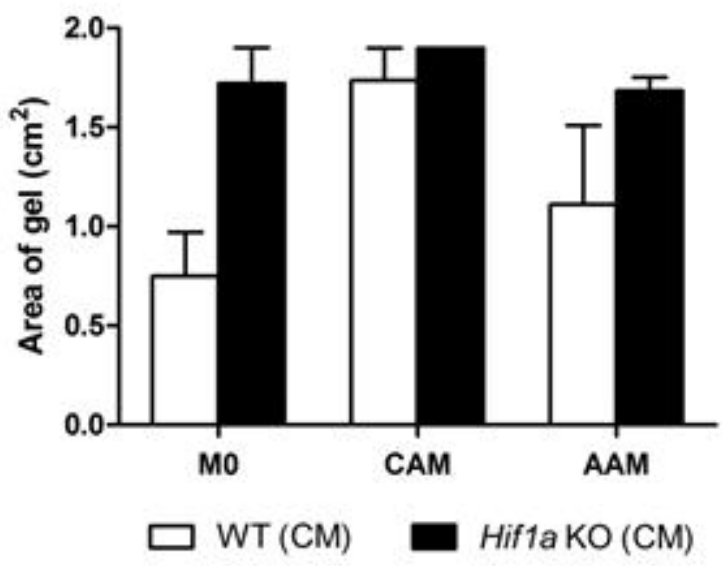

WT

Hif1a KO

D
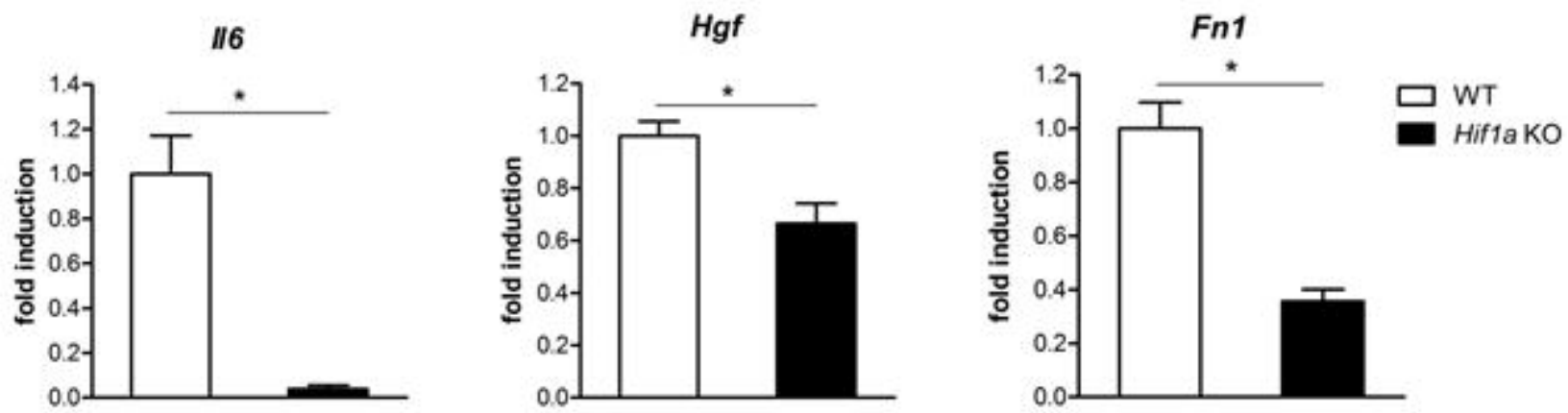
AOM/

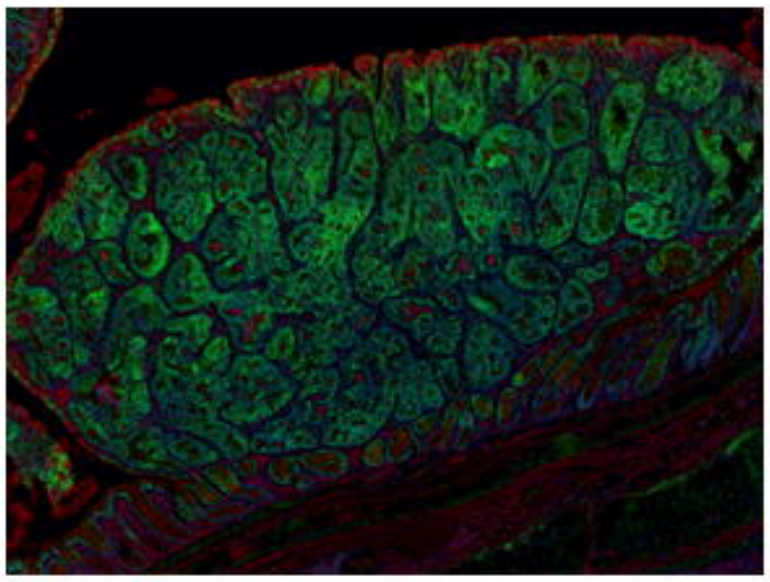

B

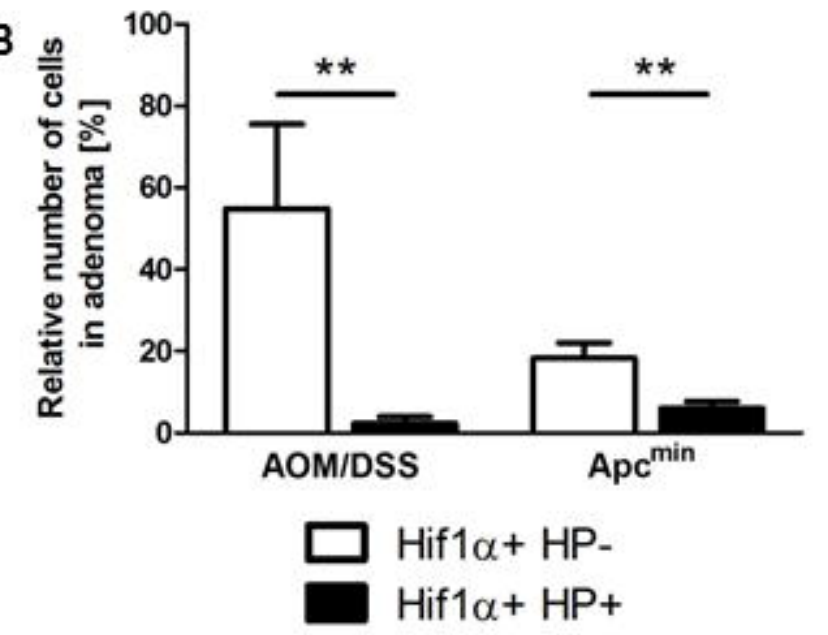

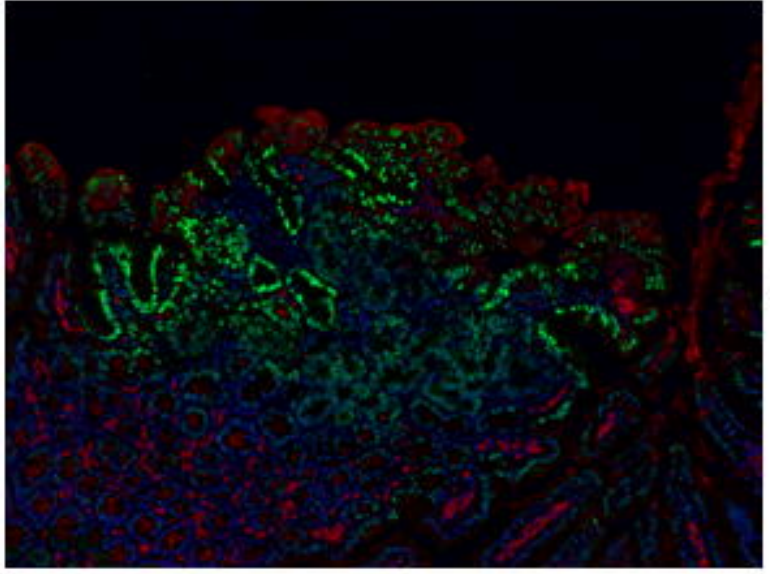

HIF-1 $\alpha$

APCmin
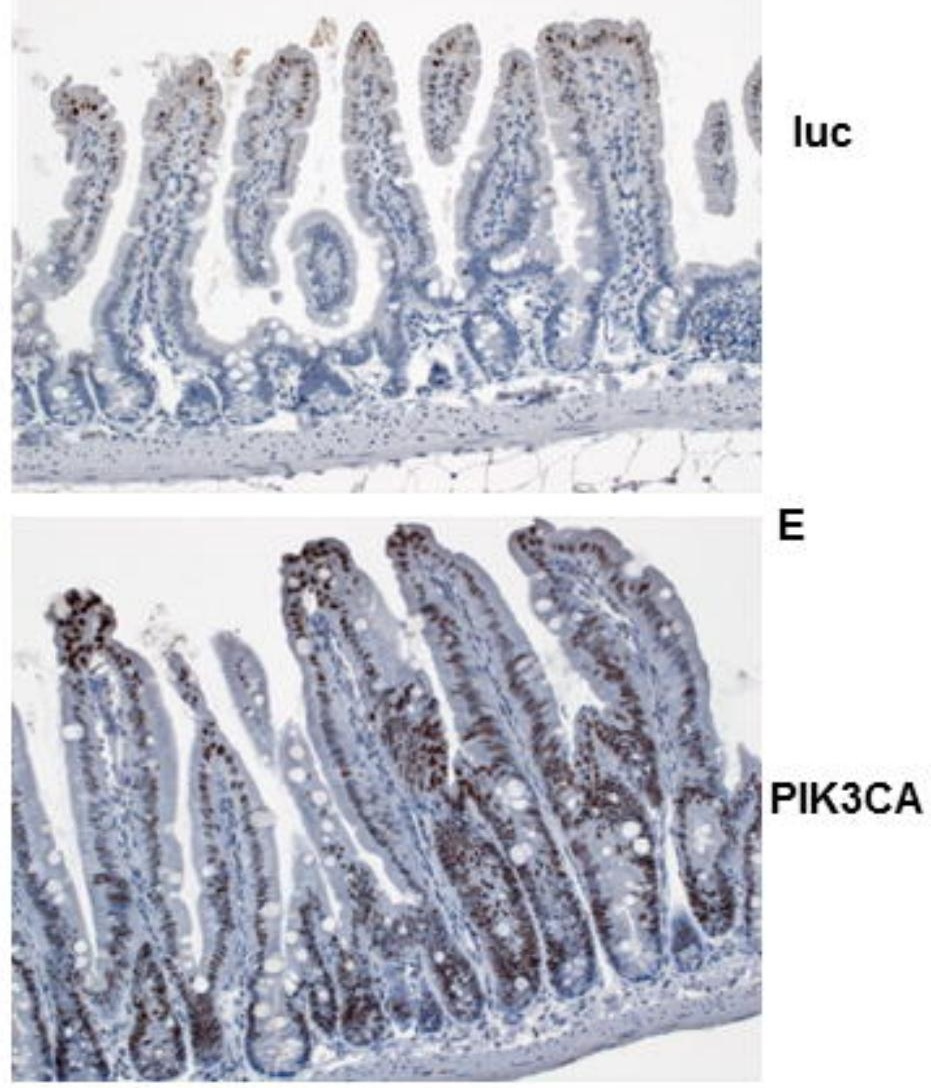

F

G

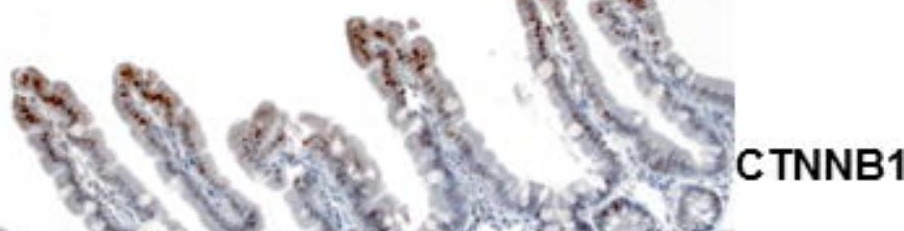

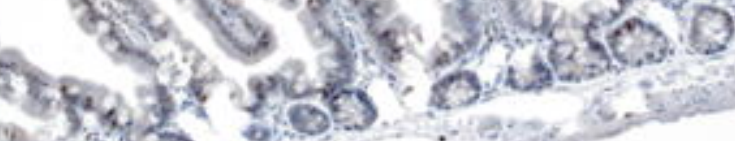
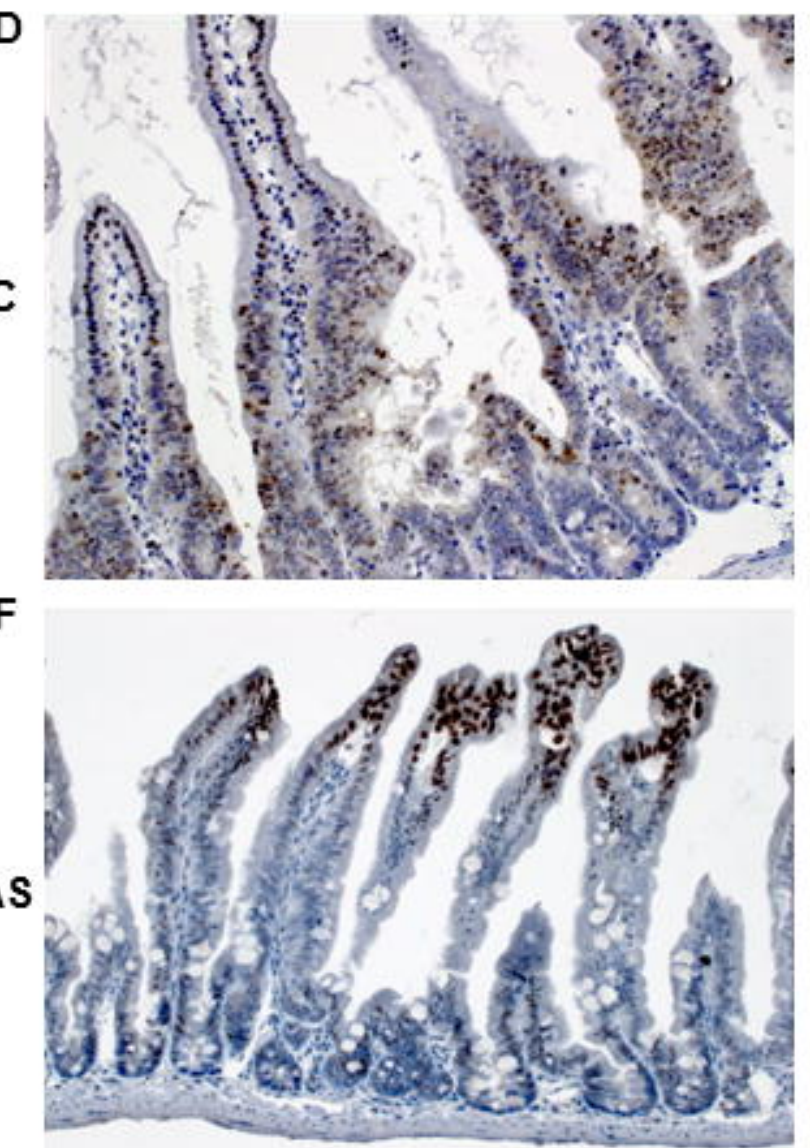

(1)

seatis: 20 